\title{
The recent decline and recovery of Indian summer monsoon rainfall: relative roles of external forcing and internal variability
}

Article

Accepted Version

Huang, X., Zhou, T., Turner, A., Dai, A., Chen, X., Clark, R., Jiang, J., Man, W., Murphy, J., Rostron, J., Wu, B., Zhang, L., Zhang, W. and Zou, L. (2020) The recent decline and recovery of Indian summer monsoon rainfall: relative roles of external forcing and internal variability. Journal of Climate, 33 (12). pp. 5035-5060. ISSN 1520-0442 doi: https://doi.org/10.1175/JCLID-19-0833.1 Available at https://centaur.reading.ac.uk/89465/

It is advisable to refer to the publisher's version if you intend to cite from the work. See Guidance on citing.

To link to this article DOI: http://dx.doi.org/10.1175/JCLI-D-19-0833.1

Publisher: American Meteorological Society

All outputs in CentAUR are protected by Intellectual Property Rights law, including copyright law. Copyright and IPR is retained by the creators or other copyright holders. Terms and conditions for use of this material are defined in the End User Agreement. 


\section{CentAUR}

Central Archive at the University of Reading

Reading's research outputs online 


\title{
The Recent Decline and Recovery of Indian Summer Monsoon Rainfall:
}

\section{Relative Roles of External Forcing and Internal Variability}

\author{
Xin HUANG $^{1,2}$, Tianjun ZHOU ${ }^{1,2,3 *}$, Andrew TURNER ${ }^{4}$, Aiguo DAI $^{5}$, \\ Xiaolong CHEN $^{1}$, Robin CLARK ${ }^{6}$, Jie JIANG ${ }^{1,2}$, Wenmin MAN ${ }^{1,3}$, James MURPHY ${ }^{6}$, \\ John ROSTRON ${ }^{6}$, Bo WU ${ }^{1,3}$, Lixia ZHANG ${ }^{1,3}$, Wenxia ZHANG ${ }^{1}$, Liwei ZOU ${ }^{1,3}$ \\ 1 LASG, Institute of Atmospheric Physics, Chinese Academy of Sciences, Beijing 10029, China \\ 2 University of Chinese Academy of Sciences, Beijing 100049, China \\ 3 CAS Center for Excellence in Tibetan Plateau Earth Sciences, Chinese Academy of Sciences \\ (CAS), Beijing 100101, China \\ 4 National Centre for Atmospheric Science and Department of Meteorology, University of Reading, \\ Reading RG6 6BB, United Kingdom \\ 5 Department of Atmospheric and Environmental Sciences, University at Albany, State University of \\ New York, Albany, NY, USA \\ 6 Met Office Hadley Centre, Exeter, EXI 3PB, United Kingdom
}

\section{Corresponding author:}

Dr. Tianjun ZHOU

LASG, Institute of Atmospheric Physics

Chinese Academy of Sciences

Beijing 100029, China.

Phone: $86-10-8299-5279$

Fax: 86-10-8299-5172

E-mail:zhoutj@lasg.iap.ac.cn

ORCID ID: https://orcid.org/0000-0002-5829-7279 
The Indian summer monsoon (ISM) rainfall affects a large population in South Asia. Observations show a decline in ISM rainfall from 1950-1999 and a recovery from 1999-2013. While the decline has been attributed to global warming, aerosol effects, deforestation, and a negative-to-positive phase transition of the Interdecadal Pacific Oscillation (IPO), the cause for the recovery remains largely unclear. Through analyses of a 57-member perturbed-parameter ensemble of model simulations, this study shows that the externally-forced rainfall trend is relatively weak and is overwhelmed by large internal variability during both 1950-1999 and 1999-2013. The IPO is identified as the internal mode that helps modulate the recent decline and recovery of the ISM rainfall. The IPO induces ISM rainfall changes through moisture convergence anomalies associated with an anomalous Walker circulation and meridional tropospheric temperature gradients and the resultant anomalous convection and zonal moisture advection. The negative-to-positive IPO phase transition from 1950-1999 reduces what would have been an externally-forced weak upward rainfall trend of $0.01 \mathrm{~mm} \mathrm{day}^{-1}$ decade $^{-1}$ to -0.15 $\mathrm{mm} \mathrm{day}^{-1}$ decade $^{-1}$ during that period, while the rainfall trend from 1999-2013 increases from the forced value of 0.42 to $0.68 \mathrm{~mm} \mathrm{day}^{-1}$ decade $^{-1}$ associated with a positive-to-negative IPO phase transition. Such a significant modulation of the historical ISM rainfall trends by the IPO is confirmed by another 100-member ensemble of simulations using perturbed initial conditions. Our findings highlight that the interplay between the effects of external forcing and the IPO needs be considered for climate adaptation and mitigation strategies in South Asia. 


\section{Introduction}

More than a fifth of the world's population lives on the Indian subcontinent and depends on the Indian summer monsoon (ISM) for their water supply (Singh et al. 2019). The ISM provides about $80 \%$ of the annual rainfall to South Asia and is the strongest component of the global monsoon system (Wang et al. 2017). Thus, understanding of ISM variability on different time scales is critical for effective risk management and adaptation planning in this densely populated and ecologically vulnerable region (Turner and Annamalai 2012).

The greatest ISM rainfall occurs over the Western Ghats, over the Himalayan foothills, in the core monsoon region over north-central India (NCI) and along the Burmese coast (Fig. 1a, c, e). Variations of summer rainfall over the core monsoon zone are widely used to measure the variability of the ISM (Gadgil 2003; Goswami et al. 2006; Bollasina et al. 2011; Jiang and Ting 2017). During the second half of the 20th century, summer rainfall decreased significantly over the NCI region, accompanied by a weakening of the large-scale ISM circulation (Bollasina et al. 2011; Salzmann et al. 2014; Roxy et al. 2015; Salzmann and Cherian 2015). Since the early 2000s however, the drying trend in NCI has ceased together with a revival of the ISM circulation (Jin and Wang 2017; Roxy 2017).

The observed long-term decline of rainfall over India in the latter half of the 20th century has been studied extensively. Several studies have attributed this to rapidly increasing anthropogenic aerosol loading, which slows down the monsoon meridional overturning circulation by reducing the land-ocean thermal contrast and inter-hemispheric energy imbalance (Bollasina et al. 2011; Salzmann et al. 2014; Guo et al. 2015; Li et al. 2015). Global warming from greenhouse gas (GHG) forcing increases atmospheric moisture holding capacity by virtue of the Clausius-Clapeyron relation. Combined with small changes in atmospheric relative humidity (Collins et al. 2013), this leads to 
increased water vapour and thus increased moisture convergence and rainfall during the ISM (May 2010; Li et al. 2015). Different sea surface temperature (SST) warming patterns can also displace regions of convection and moisture transport, contributing to the regional precipitation response (Xie et al. 2010). For example, warming over the tropical Indo-Pacific warm pool displaces South Asian rainfall with an east-west rainfall shift by inducing anomalous northerlies, which advect drier and cooler air into South Asia (Annamalai et al. 2013). Changes in land use and land cover have also been proposed as another contributor: Local evapotranspiration, a source of atmospheric moisture, has decreased as a consequence of deforestation (Paul et al. 2016; Chou et al. 2018). In addition to the above anthropogenic forcings, a negative-to-positive phase transition from the 1950s to the 1990s of the Pacific Decadal Oscillation (PDO)/Interdecadal Pacific Oscillation (IPO), whose recent cycles result mainly from internal variability (Dong et al. 2014; Hua et al. 2018), also helps to explain the total drying trend over India during this period, as highlighted by Salzmann and Cherian (2015). Using the multi-model ensemble from the 5th Coupled Model Intercomparison Project (CMIP5), the NCI drying trend associated with the PDO/IPO was comparable to that caused by anthropogenic aerosols derived from the single-forcing experiments during the period 1950-1999 (Salzmann et al. 2014).

Compared with the extensive research focusing on the drying during 1950-1999, few studies have examined the subsequent recovery of the ISM rainfall after 2000; Jin and Wang (2017) is an exception. They found that ISM rainfall shows a positive trend after around 2000 with positive anomalies lasting for multiple years, a situation that has never been observed since 1950 (Jin and Wang 2017). Thus, the recent revival of the ISM in observations differs in character from the previous decadal variations. The accelerated warming seen over South Asia that exceeds the tropical Indian Ocean warming is considered as the main driver of the ISM revival (Jin and Wang 2017; Roxy 2017). Potential causes 
for the recent warming over India include a reduction of low clouds due to decreased ocean evaporation in the Arabian Sea (Jin and Wang 2017), an increase of anthropogenic aerosols, particularly those from absorbing aerosols such as black carbon (Jin et al. 2016), changes in land-use and land cover (Paul et al. 2016), and the strengthening GHG warming effect and its dominance over other drivers (Kitoh et al. 2013). Although the observed revival of ISM rainfall appears to be underpinned by several factors, few CMIP5 models are able to reproduce the recent trend (Jin and Wang 2017). It is not entirely surprising considering the model performance in capturing the drying trend during 1950-1999 as suggested by Guo et al. (2015), Saha et al. (2014) and Salzmann and Cherian (2015). One of the explanations to the poor performance is that the externally-forced wetting trend after 2000 may be overshadowed by internal variability in individual model realizations. Since CMIP5 model historical simulations were not initialized from observed values, their output is not expected to match with observations, particularly of changes in phase associated with interannual and decadal variability. While the exact cause for the decline in ISM rainfall during 1950-1999 is still under debate, the relative contributions of external forcing and internal variability to its revival after 2000 remain unknown.

At a larger scale, the overall Northern Hemisphere summer monsoon rainfall, which also witnessed a recovery since the 1980 s, has been partially attributed to internal variability in the Pacific (Wang et al. 2013). The PDO/IPO is the main internal mode in the Pacific on interdecadal time scales, which has been linked to decadal-to-multidecadal oscillations of the ISM (Krishnan and Sugi 2003; Krishnamurthy and Krishnamurthy 2013; Joshi and Pandey 2011; Joshi and Rai 2015; Joshi and Kucharski 2017). From the 1950s to the present, the PDO/IPO has experienced a negative-to-positiveto-negative phase transition (Mantua and Hare 2002; Dong and Dai 2015; Henley et al. 2015; Joshi and Rai 2015). The positive PDO/IPO phase appears to be related to decreased ISM rainfall through 
weakened Walker and Hadley circulations induced by warm SST anomalies over the tropical centraleastern Pacific, and the opposite occurs for the IPO negative phase (Krishnan and Sugi 2003; Krishnamurthy and Krishnamurthy 2013; Dong and Dai 2015; Joshi and Kucharski 2017). The PDO/IPO can also influence the interannual variability of ISM rainfall by enhancing the El NiñoSouthern Oscillation (ENSO)-ISM relationship when ENSO and PDO/IPO are in phase, while weakening the relationship when out of phase (Krishnan and Sugi 2003; Krishnamurthy and Krishnamurthy 2013; Dong et al. 2018). It is unclear whether the PDO/IPO is the dominant internal mode responsible for both the interdecadal decline and recovery of ISM rainfall since 1950.

Determining the role of internal variability requires the exclusion of the externally-forced signal. Previous studies rely heavily on the multi-model ensemble of CMIP5 with small numbers $(<10)$ of realizations from individual models (Salzmann and Cherian 2015; Jin and Wang 2017). Different CMIP models may include different implementations of the forcings and also differ in their dynamical cores and physical parameterizations, which complicate the interpretation of the differences among individual simulations (Frankcombe et al. 2015; Dai and Bloecker 2019). Large differences exist in simulating the recent decline and recovery of ISM rainfall not only among different CMIP5 models but also among different realizations from individual models (Saha et al. 2014; Salzmann and Cherian 2015; Jin and Wang 2017). This hampers understanding of the relative role of internal variability and external forcing. To avoid these issues, a large ensemble from a single climate model is a more suitable tool for quantifying the internal variability and identifying the role of internal modes (Deser et al. 2012; Dai and Bloecker 2019). Here, we use a 57-member perturbed-parameter ensemble of simulations from the Earth system model HadCM3C (ESPPE) (Murphy et al. 2014). The relatively large ensemble size allows us to consider its ensemble mean as the externally-forced signal, whilst the deviation of an 
individual member from the ensemble mean results primarily from internal variability and secondly from its own uncertain forced response (due to parameter uncertainty) (Murphy et al. 2004). To avoid model dependence, we also analyzed the output from a 100-member ensemble of simulations generated by the Max Planck Institute Earth System Model version 1.1 (MPI-ESM) with slightly different initial conditions (Maher et al. 2018; Maher et al. 2019). In this study, we therefore aim to answer the following questions: (1) what are the relative contributions of external forcing and internal variability to the recent interdecadal variations in ISM rainfall? And (2) what are the differences and similarities of the physical mechanisms responsible for the decline in ISM rainfall during 1950-1999 and its recovery during 1999-2013?

The remainder of the paper is organized as follows. In section 2, we describe the observational data, model data and analysis methods. In section 3 , we investigate the influence of external forcing on the recent interdecadal variations of the ISM rainfall and its related physical processes. The influence of internal variability, the dominant contribution from the IPO and the underlying mechanisms are examined in section 4. In section 5, we quantify the contributions of external forcing and the observed IPO transitions to the interdecadal variations of ISM rainfall. Results derived from different large ensembles of model simulations are compared for robustness in section 6. A summary is given in section 7.

\section{Data, methods, and models}

\section{a. Observational data}

The following observational monthly gridded rainfall data are used in this study:

1) CRU version 4.02 from the Climatic Research Unit at the University of East Anglia, covering the 
period of 1901-2017 with a horizontal resolution of $0.5^{\circ} \times 0.5^{\circ}$ (Harris et al. 2014).

2) GPCC monthly product version 2018 from the Global Rainfall Climatology Centre dataset, covering the period of $1891-2016$ with a horizontal resolution of $0.5^{\circ} \times 0.5^{\circ}$ (Schneider et al. 2014).

3) UDel version 5.01 from University of Delaware, covering the period of 1900-2017 with a horizontal resolution of $0.5^{\circ} \times 0.5^{\circ}$ (Willmott and Matsuura 2001).

Here, we calculated the average of the three datasets over the period of 1901-2017 (except for 2017 , since at the time of writing GPCC ends in 2016) as the observational rainfall data (referred to as OBS) following previous studies (Huang et al. 2019; Jiang and Zhou 2019). The average OBS is interpolated to the model's resolution to compare with the model results. Results for each dataset at the raw resolutions are also shown in Fig. 1 and Fig. 3.

Observed monthly sea surface temperature (SST) data were taken from the Hadley Centre Global Sea Ice and Sea Surface Temperature (HadISST1.1) dataset produced by the Met Office, starting from 1870 up to the present with a horizontal resolution of $1.0^{\circ} \times 1.0^{\circ}$ (Rayner et al. 2003). Monthly global land-surface air temperature anomalies with respect to the 1961-90 average were taken from CRUTEM4 produced by the Climatic Research Unit at the University of East Anglia, starting from 1850 to present at a resolution of $5.0^{\circ} \times 5.0^{\circ}$ (Jones et al. 2012).

Monthly atmospheric reanalysis data were obtained from the National Centers for Environmental Prediction (NCEP)-National Center for Atmospheric Research (NCAR) reanalysis dataset (NCEP/NCAR) (Kalnay et al. 1996).

To capture the interdecadal variability in the Pacific, we used two published indices in this study for comparison. One is the PDO index from Mantua and Hare (2002; accessed at 
http://www.jisao.washington.edu/pdo), and the other is the Tripole Index (TPI) from Henley et al (2015; accessed at https://www.esrl.noaa.gov/psd/data/timeseries/IPOTPI).

\section{b. Model Data}

\section{(1) ESPPE}

We used output from a 57-member Earth system perturbed parameter ensemble (ESPPE) (Murphy et al. 2014). The ESPPE simultaneously and selectively perturbs multiple parameters within expertspecified limits in the atmosphere, ocean, sulphur cycle and terrestrial ecosystem components of the Earth system model HadCM3C, which contains a fully interactive carbon cycle and an interactive sulphur cycle scheme. The model includes the direct scattering and absorption effects along with the cloud albedo effect of aerosols (first indirect effect), while the aerosol-rainfall efficiency effect (second indirect effect) is excluded. The 57 members of the ESPPE are model variants of HadCM3C, with regular latitude-longitude grids of $2.5^{\circ} \times 3.75^{\circ}$ and $1.25^{\circ} \times 1.25^{\circ}$ in the atmosphere and ocean, with 19 and 20 vertical levels respectively (Gordon et al. 2000). Each member is spun up from an identical initial state taken from a standard HadCM3C run, providing starting conditions for the ESPPE simulations of forced climate change (Lambert et al. 2013). The historical simulations of ESPPE are integrated from 1860 to 2005 driven by observed historical changes in radiative forcing agents such as emissions of $\mathrm{CO}_{2}$ and aerosol precursors, ozone, solar variations and major volcanic eruptions following CMIP5 protocol (Taylor et al. 2012). The RCP8.5 simulations, where the radiative forcing increases and reaches around $8.5 \mathrm{~W} / \mathrm{m}^{2}$ near 2100 relative to 1750 , are then performed from 2006 to 2099 continuously following each of the 57 members of the historical run. Details of the spin-up and the perturbed parameters are provided in Lambert et al. (2013). 

the spatial pattern of ISM rainfall (Annamalai et al. 2007), the spatial structure of the IPO and the IPO-

ISM rainfall teleconnections (Joshi and Kucharski 2017). The ESPPE also reasonably simulates the climatology of ISM rainfall (Fig. 1g). The climatological monsoon rainfall centers-of-action located near the Western Ghats, over the foothills of the Himalayas and along the Burmese coast are well simulated, aiding confidence in our further analysis based on this model. More detailed information and a full evaluation of model performance for ESPPE is described in Murphy et al. (2014).

\section{(2) MPI-ESM}

To verify the results derived from the ESPPE, we also analyzed the output from a 100-member ensemble generated by the Max Planck Institute Earth System Model version 1.1 (MPI-ESM) with slightly different initial conditions (Maher et al. 2018; Maher et al. 2019). It is an update of the coupled ocean-atmosphere general circulation model submitted to CMIP5 in its low resolution configuration (MPI-ESM-LR), which has a spectral horizontal resolution of T63 $\left(\sim 1.9^{\circ}\right)$ and 47 vertical layers up to $0.01 \mathrm{hPa}$ in the atmosphere along with $1.5^{\circ}$ horizontal resolution and 40 vertical levels in the ocean. The 100 ensemble members started from different initial conditions in 1850, generated from different years of the preindustrial control simulation (piControl). The historical simulations are then integrated from 1850 to 2005 driven by observed historical changes in radiative forcing agents, including wellmixed greenhouse gases, anthropogenic sulphate aerosols, man-made land use change, monthly zonalmean ozone concentrations and major volcanic eruptions following CMIP5 protocol (Taylor et al. 2012). The simulation was extended to 2099 following the RCP 8.5 high emissions scenario. The MPIESM reasonably reproduces the climatology of ISM rainfall (Fig. 1i), in addition to the IPO-related SST patterns and the IPO-ISM rainfall relationship (Joshi and Kucharski 2017), providing further 
confidence to the model.

\section{c. Methods}

\section{(1) Statistical analysis}

A 9-year-running mean was applied to observational and model data to isolate the interdecadal signal. The Mann-Kendall (Mann 1945; Kendall 1975) non-parametric method was applied in this study to test the significance of trends. The Monte Carlo non-parametric method was used to test the significance of regression coefficients onto the filtered time series. A composite analysis was used to calculate the average of the 10 members with the strongest positive (Pos10)/negative (Neg10) IPO phase transitions. To test the significance of the trend differences between the Pos 10 members and the ensemble mean (and between Neg10 and the ensemble mean), the Student's t-test was used. Gridpoints with at least 46 out of 57 ESPPE members or 80 out of 100 MPI-ESM members (80\%) agreeing on the sign of change are marked to indicate the consistency among ensemble members.

\section{(2) Separating the externally forced signal and internal variability using the large ensemble}

Let $A(i)$ be a given variable of member $i$ from the ESPPE or MPI-ESM ensemble. Generally, time series of $A(i)$ at each grid point can be viewed as consisting of an externally-forced component (due to GHGs, aerosols, land use, solar cycles, and other external forcing) and an internally-unforced component (due to internal climate variability). In both ESPPE and MPI-ESM, the ensemble members were driven by the same external forcing. The ensemble means (EM) of $A(i)$ in each model can be taken as the model's response to external forcing, because the averaging over the ensemble members largely smooths out uncertainties among them. The model's forced response is represented as

$$
A_{\text {forced }}=(A(i))_{E M}
$$



internal variability. Thus, $A(i)$ of member $i$ in MPI-ESM is separated as:

$$
A(i)=A_{\text {forced }}+A_{\text {internal }}(i), \quad i=1,2,3 \ldots 100
$$

where $A_{\text {internal }}(i)$ is the internal component estimated as the residual of the original $A(i)$ minus the forced response. $A_{\text {internal }}(i)$ varies among different ensemble members and shows the variability associated with internal variability.

The spread of climate changes obtained from various ESPPE members contains both uncertainty in their forced response and internal variability arising from random climate variations (Murphy et al. 2004). Thus, $A(i)$ of member $i$ in ESPPE is separated as:

$$
A(i)=A_{\text {forced }}(i)+A_{\text {internal }}(i), \quad i=1,2,3 \ldots 57
$$

where $A_{\text {forced }}(i)$ represents the response to external forcing within an individual member. $A_{\text {forced }}(i)$ is different from the $A_{\text {forced }}$ (the EM of the 57 members) in ESPPE due to uncertain climate feedbacks caused by perturbed parameters. Several statistical methods have been suggested for estimating the $A_{\text {forced }}(i)$, e.g., the linear trend, high-order polynomials approximation (Hawkins and Sutton 2009, 2010) or using time series at each grid point linearly related to global-mean time series of $A$ (Dai et al. 2015). In this study, we calculated $A_{\text {forced }}(i)$ as a fourth-order polynomial of time over the years 1860-2099 following Hawkins and Sutton $(2009,2010)$. We note that the estimated $A_{\text {forced }}(i)$ may still contain some internal variability. However, since the polynomials were generated over a long time period of 240 years, we consider $A_{\text {forced }}(i)$ as primarily consisting of the externallyforced response. 
Previous studies show many different ways to calculate the index representing the PDO/IPO, for

example the EOF method (Mantua and Hare 2002) and the difference of SST anomalies between regions of the Pacific (Henley et al. 2015; Salzmann and Cherian 2015), showing an overall similarity in featuring the decadal-to-multidecadal variability of Pacific SST in observations after 1920 (Hua et al. 2018). Thus, for easier calculation and for direct comparison between observations and model simulations and comparison between ensemble members, we use the latter method to define the IPO index without applying EOF analysis, similar to Salzmann and Cherian (2015). We define the IPO index as the JJA south minus north gradient of unforced SST. In the observations, we first remove the linear trend and then calculate the SST anomalies averaged within the tropical central-eastern Pacific $\left(\mathrm{TCEP}, 170^{\circ} \mathrm{W}-90^{\circ} \mathrm{W}, 10^{\circ} \mathrm{S}-10^{\circ} \mathrm{N}\right)$ and the northern Pacific (NP, $\left.150^{\circ} \mathrm{E}-150^{\circ} \mathrm{W}, 25^{\circ} \mathrm{N}-45^{\circ} \mathrm{N}\right)$, respectively. The observational IPO index $\left(I P O_{O B S}\right)$ is defined as the 9-year running mean of the difference of detrended SST between the TCEP and the NP. Here, we used the terminology of IPO as we focus on wider Pacific-basin phenomena. We assess the IPO index derived from the HadISST1.1 dataset and find that it is highly consistent with published PDO and TPI indices in terms of both phase evolution and spatial pattern during our research period (Fig. 2).

In the ESPPE, we first separate out the internal part of SST, $S S T_{\text {internal }}(i)$, based on equation (3). The IPO index for member $(i)$ is calculated as the 9-year running mean area-averaged difference of JJA $\operatorname{SST}_{\text {internal }}(i)$ between TCEP and NP. The IPO indices in the 57 ensemble members are continuous time series with various IPO phase evolutions in the period 1950-2013. Here, we calculate the trends of IPO indices in 1950-1999 and 1999-2013 respectively. During each period, positive values represent the IPO shifting from negative to positive phases, while negative values show the opposite. To identify the internal IPO mode in ESPPE, we choose the 10 members with the strongest 
positive (Pos10) and strongest negative (Neg10) IPO phase transitions for composition during 19501999 and 1999-2013, respectively (Fig. 2f).

\section{(4) Adjustment of ISM rainfall trends based on IPO}

On the multi-decadal time scale, the contribution of the IPO to ISM rainfall trends of member $i$ in the selected time period $\tau$, for example $\tau=1950 \sim 1999,1999 \sim 2013$, is calculated as

$$
\partial_{t} p r_{I P O}(i)=r_{p r, I P O}(i) \cdot \partial_{t} I P O(i), i=1,2,3 \ldots 57 \text { or } 100
$$

$$
r_{p r, I P O}(i)=\partial p r(i) / \partial I P O(i)
$$

where $r_{p r, I P O}(i)$ is the regression coefficient of the 9-year running-mean rainfall with respect to the IPO time series of member $i$ during the period of 1950-2013. Both ESPPE and MPI-ESM reasonably reproduce the negative correlation between the IPO and ISM rainfall found in observations and both have high consistency among ensemble members (Fig. 1). $\partial_{t} I P O(i)$ is the trend of the IPO(i) index over time period $\tau$, representing the phase transition of IPO during the analysis period. $\partial_{t} p r_{I P O}(i)$ is the IPO-related rainfall trend of member $i$ in period $\tau$ and varies among the ensemble members.

In order to achieve the rainfall trends influenced by both the external forcing and the observed IPO phase transition, we employ an adjustment method following Salzmann and Cherian (2015). We adjust the original rainfall trend based on Equation (4). After the adjustment, all ESPPE members are viewed as being influenced by the same observational IPO phase evolution during 1950-2013 instead of the random IPO transitions for the raw members. The adjusted rainfall trend of member $i$ is the sum of the forced rainfall trend plus the internal component of the rainfall trend with an adjustment term depending on the difference between the simulated and observed IPO trends $\left(\partial_{t} I P O_{O B S}\right)$, which is expressed as: 
where

$$
\partial_{t} p r_{\text {internal_adj }}(i)=\partial_{t} p r_{\text {internal }}(i)+\alpha_{\text {internal }}(i),
$$

where

$$
\alpha_{\text {internal }}(i)=-r_{p r, I P O}(i) \cdot\left(\partial_{t} I P O(i)-\partial_{t} I P O_{O B S}\right),
$$

where $\partial_{t} p r_{\text {internal_adj }}(i)$ is the adjusted internal rainfall trend calculated by adding the original internal trend to an adjustment term, $\alpha_{\text {internal }}(i)$. As shown in equation (8), the adjustment term takes the observational IPO phase transition into consideration. $\partial_{t} p r_{\text {internal_adj }}(i)$ can be viewed as the internal rainfall trends after replacing the raw IPO phase transitions with the observational one. Thus, the EM of the $\partial_{t} p r_{\text {internal_adj }}(i)$ represents the observed IPO's contribution to the rainfall trend. The IPO-adjusted total rainfall trend, $\partial_{t} p r_{a d j}(i)$, is the sum of the simulated externally forced signal $\left(\partial_{t} p r_{f o r c e d}\right)$ and the adjusted internal trend. After the above adjustment, the rainfall trend uncertainty among the 57 ESPPE members (or 100 MPI-ESM members) related to their random IPO phase transition is narrowed but the other internal uncertainty remains. The EM of $\partial_{t} p r_{a d j}(i)$ represents the rainfall changes in response to external forcing and the observed IPO phase transition.

\section{(5) Moisture budget analysis}

The moisture-budget analysis method has been used in many studies (Chou and Neelin 2004; Chou et al. 2009; Seager et al. 2010). Here we apply it to understand the physical mechanisms governing historical changes in ISM rainfall. Using pressure-level coordinates, the moisture budget equation is expressed as:

$$
\partial_{t} q=-P+E-<\nabla \cdot(\boldsymbol{V} q)>+ \text { res }
$$


where $\partial_{t} q$ is the time derivative of vertically integrated moisture in the atmosphere, which is small and can be neglected. $P$ and $E$ are rainfall and evaporation, $\boldsymbol{V}$ and $q$ are horizontal winds and specific humidity; res is the residual term including the moisture transport by surface processes due to topography and transient eddies ( $\mathrm{Li}$ et al. 2013). For long-term trends, equation (9) is mainly balanced by $P-E$ and $-<\nabla \cdot(\boldsymbol{V} q)>$. Triangle parentheses indicate a vertical integration from the surface to the tropopause. $-\langle\nabla \cdot(\boldsymbol{V} q)\rangle$ refers to the vertically integrated moisture flux convergence. We separate $\boldsymbol{V}=\overline{\boldsymbol{V}}+\boldsymbol{V}^{\prime}$ and $q=\bar{q}+q^{\prime}$, where the overbars and primes indicate long-term means and departures, respectively, as is the convention. Equation (9) can be transformed to:

$$
P^{\prime}-E^{\prime}=-<\nabla \cdot\left(\overline{\boldsymbol{V}} q^{\prime}\right)>-<\nabla \cdot\left(\boldsymbol{V}^{\prime} \bar{q}\right)>-<\nabla \cdot\left(\boldsymbol{V}^{\prime} q^{\prime}\right)>+ \text { res }
$$

where the first, second and third terms on the right-hand side of equation (10) denote thermodynamic, dynamic and nonlinear components of moisture convergence terms, separated from the total vertically integrated moisture flux convergence. They are contributed by changes of moisture only, circulation only and both moisture and circulation, respectively.

Considering the continuity equation, the dynamic components of moisture convergence can be further decomposed into three terms as:

$$
-<\nabla \cdot\left(\boldsymbol{V}^{\prime} \bar{q}\right)>=-<u^{\prime} \partial_{x} \bar{q}>-<v^{\prime} \partial_{y} \bar{q}>-<\omega^{\prime} \partial_{p} \bar{q}>
$$

where $u^{\prime}, v^{\prime}$ and $\omega^{\prime}$ are the zonal wind, meridional wind and vertical pressure-velocity anomalies, respectively. The three terms on the right-hand side of equation (11) denote zonal, meridional and vertical dynamic components of the moisture convergence term, respectively.

\section{Impact of external forcing}




\subsection{Influence of external forcing on ISM rainfall trends}

From 1950 to 1999, a decreasing rainfall trend was seen over north-central India (NCI) in the observations (Fig. 3a, b, c, m; significant in all datasets, except GPCC), consistent with previous studies (Bollasina et al. 2011; Salzmann et al. 2014; Salzmann and Cherian 2015). The multi-dataset average (referred to as OBS) trend is $-0.11 \mathrm{~mm} \mathrm{day}^{-1}$ decade $^{-1}$ for this period (Fig. $3 \mathrm{~g}$ ). To determine the role of external forcing in this drying trend, we examined the ESPPE's ensemble mean (EM). The EM can be considered as the response to external forcing. In the EM, a dipole pattern between a drying trend close to the Himalayan foothills and a wetting trend further south was seen (Fig. 3h). The bipolar rainfall change gave an overall insignificant trend of $0.01 \mathrm{~mm} \mathrm{day}^{-1} \mathrm{decade}^{-1}$ ( $p$ value is 0.55 ) over the NCI, indicating little role of external forcing in the observed drying (Fig. 3n).

Following the decreasing trend, the observed NCI rainfall reversed to a significant increasing trend during 1999-2013 (Fig. 3d, e, f), with a multi-dataset average of $0.66 \mathrm{~mm} \mathrm{day}^{-1}$ decade $^{-1}$ (Fig. 3j, $\mathrm{m})$. Unlike the drying trend, this recovery of monsoon rainfall was partially reproduced by the ensemble mean of ESPPE. The EM shows a homogenous increasing trend over the NCI region of 0.42 mm day ${ }^{-1}$ decade $^{-1}$ (Fig. 3k, 3n), indicating a role for external forcing in the observed revival during this period.

\subsection{Physical mechanisms}

To explore why external forcing induces different rainfall trends during 1950-1999 and 19992013, we compared the moisture budget terms of the two periods (Equations (9-10)). Figure 4a shows quantitative results of the moisture budget analysis on the NCI rainfall trends. Rainfall change is balanced by the changes of evaporation, dynamic and thermodynamic components and a nonlinear 
term. The dynamic component is further separated into vertical, zonal and meridional dynamic components of moisture convergence. During 1950-1999, opposing trends of dynamic and thermodynamic moisture convergence lead to the weak NCI rainfall trend (Fig. 4a). Their spatial patterns show that the thermodynamic component increases the NCI rainfall homogenously (Fig. 4d), while the dynamic component results in the bipolar rainfall trend (Fig. 4b). Further decomposition of the dynamic component shows that the dominant contribution comes from the vertical dynamic moisture convergence (Fig. 4a, f), while the role of horizontal dynamic components is small (Fig. 4a, h). In contrast to the pre-1999 period, the accumulative influence of the dynamic and thermodynamic components results in the increasing rainfall trend after 1999 (Fig. 4a, c, e). Furthermore, the vertical and zonal dynamic components comparably contribute to the increasing rainfall over southern and northern India, respectively (Fig. 4a, g, i). These calculations reveal that while the thermodynamic component related to changes in specific humidity is consistently increasing during the two periods, the dynamic component indicating monsoon circulation changes caused by external forcing are different.

We further investigated the interdecadal variations of specific humidity and monsoon circulation caused by external forcing. During 1950-1999, atmospheric moisture content increased with GHGinduced global warming (Fig. 5a, e, g), which explains the positive trend of the thermodynamic component in this period. Meanwhile, a positive Indian Ocean (IO) dipole warming pattern was seen with increased external forcing (Fig. 5e). The relatively larger warming trend in the western IO SST helps maintain the anomalous easterly winds along the equator (Dong and Zhou 2014; Roxy et al. 2015). The divergent circulation induces anomalous descent and decreased rainfall from the Maritime Continent to tropical southern IO (Fig. 5c). The rainfall is then increased over the western and southern 
Indian subcontinent and adjacent seas due to anomalous moisture convergence associated with changes in local Hadley-type circulation (Fig. 5c, 5g). Furthermore, the increased anthropogenic aerosols subdue the warming over the Indian subcontinent as indicated in previous studies (Bollasina et al. 2011; Guo et al. 2015; Jin and Wang 2017). The regional surface cooling near the Himalayan foothills decreases local rainfall via the vertical dynamic term (Figs. 4f, 5e).Thus, the forced zonally nonuniform warming over the tropical IO and local surface cooling together explain the bipolar trend pattern of dynamic moisture convergence (Fig. 4b). Compared to the pre-1999 period, atmospheric moisture content increased faster after 1999 due to enhanced global warming (Fig. 5b), resulting in a larger positive trend in the thermodynamic component (Fig. 4e). Moreover, the most noticeable difference in monsoon circulation changes between pre- and post-1999 period is the anomalous southeasterly winds over the Bay of Bengal (Fig. 5c, 5d). After 1999, the stronger land-sea thermal contrast between the East Asia and the western north Pacific Ocean intensifies the low-level subtropical anticyclone and decreases rainfall over the western Pacific (Liu et al. 2012; Fig. 5d, 5f), which then incites a Rossby wave to its west (Annamalai et al. 2013). The resultant anomalous south-easterly winds over the Bay of Bengal dynamically increase rainfall over India by through inducing anomalous ascent and moisture advection (Figs. 4g, 4i, 5d, 5h).

The above results suggest that external forcing has partially played a role in modulating the interdecadal variations of ISM rainfall during 1950-2013. However, the insignificant rainfall trend caused by external forcing from 1950-1999 is different from that observed. Also, the forced positive trend after 1999 is relatively weaker than the OBS. These indicate the non-negligible contributions of internal variability during both periods that shall be examined next.

\section{Impact of internal variability}




\subsection{Influence of internal variability on ISM rainfall trends}

The spread of rainfall trends is large among the 57 members during both periods, as demonstrated by the large standard deviations of rainfall trends across the ensemble members (Fig. 3i, 1). Histograms demonstrating spread in quantitative rainfall trends among the 57 members are show in Figure $6 \mathrm{a}$ and 6b. During 1950-1999, 27 of the 57 simulations show negative trends for NCI rainfall (Fig. 6a). The NCI rainfall trends from the ensemble members range from -0.25 to $0.54 \mathrm{~mm} \mathrm{day}^{-1}$ decade $^{-1}$ during this period. On the other hand, the spread among ensemble members ranges from -0.82 to $2.00 \mathrm{~mm}$ day $^{-1}$ decade $^{-1}$ during 1999-2013 (Fig. 6b). Despite being forced by increasing GHG, there are still 14 out of the 57 ESPPE realizations that show negative NCI rainfall trends during this period. The spread of ensemble members includes the influence of both the response uncertainty (due to uncertainties in model parameters; $\left.p r_{\text {uncertain }}(i)\right)$ and internal variability $\left(p r_{\text {internal }}(i)\right.$; Equation (3)). These two different sources of uncertainty are partitioned with a fourth-order polynomial following previous studies (Hawkins and Sutton 2009, 2010). After dividing the NCI rainfall trends into the above two parts, the trend uncertainty caused by internal variability is larger than that caused by the uncertain forced response (Fig. 6a, b). Furthermore, the correlation coefficients between the original rainfall trends $(\operatorname{pr}(i))$ and the trends of the internal part $\left(\operatorname{pr}_{\text {internal }}(i)\right)$ are 0.78 and 0.99 , respectively, for the period of 1950-1999 and 1999-2013 (Fig. 6c, d). The significant correlation coefficients imply that at the regional scale the total spread of rainfall trend is dominated by the uncertainties arising from internal variability during both historical periods. Thus, internal variability can greatly modulate both the decline during 1950-1999 and the recovery during 1999-2013 of ISM rainfall.

\subsection{IPO helps modulate ISM rainfall trends}


The PDO/IPO has been shown to have an influence on decadal rainfall variations over India in previous studies (Krishnan and Sugi 2003; Krishnamurthy and Krishnamurthy 2013; Joshi and Pandey 2011; Dong and Dai 2015; Joshi and Rai 2015). The observed PDO/IPO experienced a negative-topositive-to-negative phase evolution during 1950-2013 (Dong and Dai 2015; Joshi and Rai 2015; Dong

et al. 2018), as also indicated by an IPO index defined in terms of SST gradients between the tropical central-eastern Pacific (TCEP) and the Northern Pacific (NP) (see Methods; Fig. 2). The switch points are seen around the late 1970s and around 2000 (Fig. 2e). Due to the combined influence of external forcing and internal variability in the observations, the negative correlation between temporal variations of the IPO and NCI rainfall during 1950-2013 is only weak. However, the observed IPO index still shows an increasing trend of $0.66 \mathrm{~K} \mathrm{decade}^{-1}(p<0.01)$ during 1950-1999 and a decreasing trend of $-0.37 \mathrm{~K} \mathrm{decade}^{-1}$ ( $p$ value is 0.11 due to the small number of years) during 1999-2013. Since the negative-to-positive IPO phase transition has been suggested to help explain the 1950-1999 ISM drying trend (Salzmann and Cherian 2015), the positive-to-negative IPO transition afterwards may have a link with the recent wetting trend.

To determine whether the IPO evolution helps modulate ISM changes, we used the ESPPE to quantify the principal internal mode responsible for the spread in the rainfall trends. The 57 SST trend patterns derived from ESPPE members are regressed onto the 57 values of internal NCI rainfall trends through the member index during both periods (Fig. 6e, f). This regression method helps identify the dominant internal variability in the ocean related to the trend spread of monsoon rainfall. The results of both periods feature a negative correlation in TCEP and a positive correlation in NP (Fig. 6e, f), which is similar to the observed IPO-like pattern and the internal IPO mode of ESPPE (Fig. 2). To directly confirm the influence of the IPO, we chose the 10 members with the strongest positive IPO 
phase transitions (Pos10) during 1950-1999 and the 10 members with the strongest negative phase transitions (Neg10) during 1999-2013, respectively (Fig. 2f). The composites of Pos10 and Neg10 indeed reproduce a decreasing trend of NCI rainfall over 1950-1999 and an increasing trend afterwards, respectively (Fig. 3n). The differences between the chosen members and the ensemble mean (Pos10EM or Neg10-EM) suggest that the IPO helps modulate both the ISM decline during 1950-1999 and its recovery over 1999-2013.

\subsection{Physical mechanisms of IPO modulating the decline and recovery of ISM rainfall}

Our large ESPPE also offers the opportunity to re-examine how IPO phase transitions help modulate the interdecadal decline and recovery of ISM rainfall in 1950-2013. Through a moisture budget analysis on the rainfall trend difference between the Pos10-EM during 1950-1999 and Neg10EM during 1999-2013, the dynamic component of moisture convergence appears to play a dominant role in modulating the NCI rainfall (Fig. 7a), which is also shown in its spatial patterns (Fig. 7b-e). Further decomposition of the dynamic component shows that the dominant contributions come from the vertical and zonal moisture convergence (Fig. 7a, f-i). The anomalous vertical moisture convergence covers a wide spatial scale including the Indian subcontinent and adjacent seas (Fig. 7f, g), similar to the anomaly rainfall pattern (Fig. $7 \mathrm{~b}, \mathrm{c}$ ), while the zonal moisture convergence shows a bipolar pattern that leading to the rainfall anomalies over northern India (Fig. 7h, i). These results suggest a consistently key role of anomalous vertical motion and zonal moisture advection in modulating both the decline and the recovery of ISM rainfall by the IPO.

To investigate the anomalous circulation associated with the IPO phase transitions, we further calculated the composite differences of Pos10-EM in 1950-1999 and Neg10-EM in 1999-2013 (Fig. 
8). During 1950-1999, warm SST anomalies over the TCEP weaken the Walker circulation (Fig. 8a). The 200hPa velocity potential trend differences of Pos10-EM exhibit a decrease (divergence) over the central-eastern Pacific and an increase (convergence) across $40^{\circ} \mathrm{E}-140^{\circ} \mathrm{E}$, especially over the tropical Indian Ocean and Indian subcontinent (Fig. 8a). The upper-level convergence over India and the adjacent seas corresponds to the anomalous descending motion, which suppresses ISM convection and rainfall (Fig. 7f). Meanwhile, the depressed convection over India establishes two anomalous anticyclones to its northwest and southwest asymmetrically (Fig. 8c, e) according to the Matsuno-Gill theory (Matsuno 1966; Gill 1980). The anomalous circulation opposes the climatological monsoon flow over India and weakens the cross-equatorial monsoon circulation (Fig. 8e). The westerlies on the northern flank of the northwest anticyclonic anomalies advect relatively drier air from the Eurasian landmass (Parker et al. 2016) (i.e. Pakistan, Afghanistan) to the west of NCI (Fig. 8e). The dry advection decreases rainfall over northern India via zonal moisture convergence (Fig. 7h). The anomalous low-level westerlies over the tropical central western Pacific and South China Sea (Fig. 8e) associated with the weakened Walker circulation also help to maintain the zonal dry advection from the west (Chen and Zhou 2015).

Accompanying the IPO phase shift from positive to negative during 1999-2013, the anomalous circulation shows opposite patterns associated with cold SST anomalies over the TCEP. The Walker circulation is enhanced as indicated by the $200 \mathrm{hPa}$ velocity potential trend difference of Neg10-EM (Fig. 8b). The upper-level divergence represents the anomalous ascent over India and the adjacent seas, which enhances ISM convection and rainfall (Fig. 7g). Similarly, the enhanced convection over India establishes two anomalous asymmetric cyclones to its west, leading to the strengthened monsoon circulation (Fig. 8d, f). Easterlies over the northern Indian subcontinent advect relatively wetter air 
from the Bay of Bengal and Indochina peninsula into the east of NCI (Fig. 8f). The moisture convergence increases rainfall over northern India via positive zonal moisture convergence (Fig. 7i). Furthermore, the anomalous low-level easterlies over the tropical central western Pacific and South China Sea are also evident (Fig. 8f). Our results suggest consistent atmospheric processes related to the IPO appear to work in both directions during the two periods of decline and revival of ISM rainfall.

Previous studies have also suggested that the interdecadal variations of ISM rainfall during 19502013 are closely related to changes in the meridional thermal contrast extending from the surface to the mid-upper troposphere (Jin and Wang 2017; Roxy 2017). Thus, in addition to the above changes in large-scale circulation, we further show that another mechanism of the IPO helps modulate the interdecadal variations of ISM via influencing the related meridional thermal contrast (Figs. 9-10).

Accompanying the positive IPO phase transition during 1950-1999, the trend differences of Pos 10-EM exhibit warming SST anomalies over the tropical Indian Ocean $\left(40^{\circ} \mathrm{E}-100^{\circ} \mathrm{W}, 10^{\circ} \mathrm{S}-25^{\circ} \mathrm{N}\right)$ and cooling surface temperature over the landmass to the north of India $\left(65^{\circ} \mathrm{E}-90^{\circ} \mathrm{E}, 30^{\circ} \mathrm{N}-45^{\circ} \mathrm{N}\right)(\mathrm{Fig}$. 9a). The strong surface warming of the Indian subcontinent is consistent with the decreased ISM rainfall in this period (Fig. 8c). From 1999 to 2013, the trend of Neg10-EM shows opposite land-sea surface temperature changes accompanying the IPO phase shift from positive to negative (Fig. 9b). As shown in previous studies (Dong et al. 2016), the IPO has a footprint on decadal SST variations in the Indian Ocean via atmospheric adjustments caused by changing surface heat fluxes, sea surface height and thermocline depth. Meanwhile, the IPO also has a negative correlation with surface temperature in a band across the Mediterranean-Middle East-northern India through anomalous atmospheric circulation (Dong and Dai 2015). The composite surface thermal contrast between the tropical Indian Ocean and the landmass north of India shows a strengthening tendency during 1950-1999, followed 
by a weakening tendency during 1999-2013, similar to the time variations derived from observations (Fig. 9c). However, the surface temperature over land and the SST of Indian Ocean are at different pressure levels because of local topography. The role of the tropospheric temperature gradients at the same pressure level on ISM variations should be considered (Dai et al. 2013).

The vertical wind shear over South Asia has been widely used to define the strength of ISM (Webster and Yang 1992). Considering the thermal wind relationship, similar temperature gradients in the mid-upper layers play a larger role on the vertical wind shear over the ISM region than gradients in the lower troposphere (Dai et al. 2013). Thus, the IPO can affect the ISM more effectively through its influence on the meridional thermal contrast in the mid-upper troposphere (Fig. 10). During 19501999, the 500-200hPa tropospheric thickness trend of Pos10-EM increases over the tropical Indian Ocean $\left(60^{\circ} \mathrm{E}-100^{\circ} \mathrm{E}, 10^{\circ} \mathrm{S}-10^{\circ} \mathrm{N}\right)$ and decreases over Eurasia $\left(60^{\circ} \mathrm{E}-100^{\circ} \mathrm{E}, 25^{\circ} \mathrm{N}-45^{\circ} \mathrm{N}\right)$, while an opposite trend pattern occurs in 1999-2013 for Neg10-EM (Fig. 10a, b). The composite variations of meridional thermal contrast in the troposphere based on Pos10-EM in 1950-1999 and Neg10-EM in 1999-2013 feature an increasing trend in the former period and a decreasing trend afterwards (Fig. 10c). In response to the SST anomalies over TCEP, the local convective latent heating changes, which then affects the tropical tropospheric temperature and thus the meridional tropospheric temperature gradient over the Indian sector (Chiang and Sobel 2002). Previous studies (Goswami and Xavier 2005; Xavier et al. 2007) have discussed how ENSO-related tropical SST anomalies influence ISM via changes in tropospheric temperatures. Here, we show that IPO-related tropical Pacific SST anomalies can also modulate the ISM on decadal-to-multidecadal time scales through similar processes, thus extending the ENSO-related tropospheric temperature mechanism to a longer time scale. With the detailed investigation of the IPO's dynamical mechanisms showed above, our study helps reconcile 
different explanations for the recent interdecadal variations in ISM rainfall proposed by previous studies (Krishnamurthy and Krishnamurthy 2013; Roxy et al. 2015; Salzmann and Cherian 2015; Jin and Wang 2017).

\section{Adjustments to simulated ISM rainfall trends considering both external forcing and observed IPO evolution}

Both external forcing and internal variability (with a non-negligible contribution from the IPO) contribute to the recent decline and recovery of ISM rainfall. To further quantify the relative contributions of external forcing and the IPO to the rainfall trends, we applied an 'adjustment' method to the 57 ESPPE members to take the observational IPO phase transition into account with the externally-forced change, following Salzmann and Cherian (2015). The raw ESPPE members have different IPO phases due to its random realizations in the freely-run coupled model. The 'adjustment' method first removes the raw IPO-related rainfall trends and then adds the influence of the observed IPO phase transition through regression within each member (see Methods; Equation (6)-(8)). Compared to the EM without the adjustment (Fig. 3h, k), which represents the response to external forcing only, the EM of the adjusted ESPPE members (Fig. 11b, e) is the combination of the response to external forcing and the influence of the observed IPO phase transition (Fig. 11a, d). Here, the adjustment to the ISM rainfall trend during 1950-1999 also provides a comparison with the results of Salzmann and Cherian (2015), which were derived from the CMIP5 multi-model ensemble.

After considering the influence of the observed IPO evolutions, the EM of the adjusted internal part of rainfall derived from ESPPE, representing the rainfall changes caused by the observed IPO transition, shows a strong drying trend over the ISM region during 1950-1999 (Fig. 11a). Meanwhile, 
it shows an additional wetting trend over India during 1999-2013 (Fig. 11d). In both time periods, the EMs of the adjusted rainfall trends (see Methods; $\partial_{t} p r_{a d j}(i)$ ), which represent the combined influences of external forcing and the observational IPO phase transition, are close to the observed ISM rainfall trends (Fig. 11b, e).

Quantitatively, during 1950-1999, the adjustment considering the observed negative-to-positive IPO transition decreases the NCI rainfall trend from $0.01 \pm 0.14$ to $-0.15 \pm 0.13 \mathrm{~mm} \mathrm{day}^{-1} \mathrm{decade}^{-1}$ in ESPPE (Fig. 11c), which is comparable to the adjustment from $-0.02 \pm 0.06$ to $-0.11 \pm 0.08 \mathrm{~mm}^{-1} \mathrm{day}^{-1}$ decade $^{-1}$ derived from the CMIP5 multi-model ensemble by Salzmann and Cherian (2015). The IPOinduced NCI rainfall trend is $-0.16 \mathrm{~mm} \mathrm{day}^{-1}$ decade $^{-1}$ in ESPPE during this period. During the revival in 1999-2013, the adjustment increases the simulated NCI rainfall trend from $0.42 \pm 0.61$ to $0.68 \pm 0.54$ mm day ${ }^{-1}$ decade $^{-1}$ (Fig. 11f). Taking the IPO shift from a positive to a negative phase into consideration together with the external forcing, the adjusted NCI rainfall trend is close to the observed wetting trend of $0.66 \mathrm{~mm} \mathrm{day}{ }^{-1}$ decade $^{-1}$, with the IPO-induced trend of $0.26 \mathrm{~mm} \mathrm{day}^{-1}$ decade $^{-1}$. Moreover, the signal-to-noise ratio of rainfall trends among ESPPE members increases from 0.07 to 1.15 in $1950-1999$ and from 0.69 to 1.26 in 1999-2013; thus, it becomes much higher after the adjustment than before in both time periods. It indicates that the uncertainties in ISM rainfall trends among the 57 members can be narrowed through the adjustments which allow them to have the same observed IPO phase transitions. These results suggest that the adjusted ISM rainfall trends, taking the observed IPO evolution into account as well as the external forcing, becomes close to those observed with a narrowed range of uncertainty. Thus, for effective near-future climate adaptation and mitigation efforts, the IPO's phase transitions must be considered in addition to anthropogenic climate change in South Asia. 


\section{Comparison of different large ensembles of model simulations}

Our results derived from the ESPPE provide a comparison with those from the CMIP5 multimodel ensemble of Salzmann and Cherian (2015) and Jin and Wang (2017). We further confirmed the results with another 100-member ensemble of simulations based on the MPI-ESM which has been recently completed and made available (Maher et al. 2019). As the largest perturbed-initialization ensemble using a comprehensive climate model, it allows us to directly consider the differences between the individual members as arising from internal variability, without the need for any complicated statistical separation method. The EM of the MPI-ESM also indicates that external forcing partly explains the interdecadal variations of ISM rainfall (Fig. 12a, b), though the forced rainfall trends are quantitatively different from that of the ESPPE (Fig. 3g, k), as expected. The large spread of ISM rainfall trends among ensemble members caused by internal variability is also evident during both periods (Fig. 12c, d). The regression patterns of SST trends with respect to the NCI rainfall trends across the 100 MPI-ESM members confirm that the IPO helps modulate the interdecadal variability of ISM rainfall (Fig. 13a, b). The composites of Pos10 members from 1950-1999 and Neg10 members from 1999-2013 in MPI-ESM ensemble, respectively, also reproduce the recent decline and recovery of ISM rainfall (Fig. 12e-g). Moreover, the adjusted ISM rainfall taking into account the influence of the observed IPO evolution with external forcing shows a decreasing trend during 1950-1999 and an increasing trend during 1999-2013, close to the observations (Fig. 13c-f). This strongly supports our earlier results derived from the ESPPE.

\section{Summary and concluding remarks}

In this study, we investigated the influence of historical external forcing and internal variability 
on interdecadal variability of ISM rainfall during 1950-2013 using a 57-member ensemble of ESPPE and a 100-member ensemble of MPI-ESM. We also explored possible physical mechanisms related to the recent drying and subsequent recovery. The main results are summarized in Fig. 14 and given below:

(1) Role of external forcing: In ESPPE's ensemble mean, an insignificant externally-forced ISM rainfall trend was seen from 1950-1999 followed by a significant increasing trend from 1999-2013. During 1950-1999, atmospheric moisture content increased due to global warming, which enhances ISM rainfall thermodynamically. Dynamically, the zonally nonuniform warming over the tropical Indian Ocean induces anomalous ascent over southern and western India associated with increase local rainfall. Meanwhile, a cooling trend of surface temperature close to the foothills of the Himalayas induces anomalous descent reducing rainfall over northern India. Overall, the competing dynamic and thermodynamic processes appear to result in the overall insignificant rainfall trend. During 1999-2013, atmospheric moisture content continued to increase associated with enhanced global warming. At the same time, dynamic moisture convergence has also strengthened related to enhanced land-sea thermal contrast between East Asia and the western north Pacific Ocean. The accumulative impact of the dynamic and thermodynamic processes results in the increasing ISM trend during this period. As a result, external forcing partly contributes to the observed interdecadal variability of ISM rainfall.

(2) Role of internal variability: From our analysis, it appeared that neither of the trends of ISM rainfall pre- and post-2000 can be solely explained as a response to external forcing. Internal variability also had a significant role, mainly arising from the IPO. The negative-to-positive-tonegative IPO evolution during 1950-2013 modulates the ISM by inducing anomalous vertical 
motion and zonal moisture convergence related to an anomalous Walker circulation. The IPO can also influence ISM variability through modulating the meridional thermal contrasts over South Asia. The underlying mechanisms of the IPO in modulating the recent ISM rainfall variability appear to be valid in both directions during the two periods.

(3) Relative contributions of external forcing \& internal variability: Quantitatively, the observed negative-to-positive IPO phase transition during 1950-1999 induced a negative NCI rainfall of $0.16 \mathrm{~mm} \mathrm{day}^{-1}$ decade $^{-1}$, which decreased the externally-forced rainfall trend from 0.01 to -0.15 mm day ${ }^{-1}$ decade $^{-1}$. During 1999-2013, the positive-to-negative IPO transition caused a positive NCI rainfall trend of $0.26 \mathrm{~mm} \mathrm{day}^{-1}$ decade $^{-1}$, which increased the forced trend of 0.42 to $0.68 \mathrm{~mm}$ day $^{-1}$ decade $^{-1}$. The ensemble mean of the adjusted rainfall trends $\left(\partial_{t} p r_{a d j}(i)\right)$, which represent the combined influences of external forcing and the observational IPO phase transition, are close to the observed rainfall trends of -0.11 and $0.68 \mathrm{~mm} \mathrm{day}^{-1}$ decade $^{-1}$ pre- and post-2000, respectively. Moreover, the signal-to-noise ratios have also become greater after the adjustment, indicating that the uncertainties in ISM rainfall trends among the ensemble members are reduced after modifying their IPO phase transitions to match those of observations.

(4) Comparison of different ensembles: We also verified the results with a second ensemble of 100 simulations based on the MPI-ESM. Differences were found in the quantitative rainfall trends caused by external forcing between the two ensembles. However, the MPI-ESM ensemble supports the main results given by the ESPPE that the IPO helps modulate the recent decline and recovery of ISM rainfall. By adjusting the simulated rainfall trends, according to the observed IPO phase transition, both ensembles successfully reproduced the observed decline in 1950-1999 and the recovery afterwards. 

observed variability of ISM rainfall, with the IPO identified as a contributing internal mode. We also

654 analysed the physical processes through which external forcing and the IPO modulate the ISM, respectively. Our results reveal, for the first time, the linkage between and consistency among different explanations of the decadal-to-multidecadal variations in ISM rainfall proposed in the literature (Goswami and Xavier 2005; Xavier et al. 2007; Krishnamurthy and Krishnamurthy 2013; Salzmann and Cherian 2015; Jin and Wang 2017). Our findings also pose a new perspective for future projections of ISM, that the phase transitions of the IPO must be considered in addition to the response to external forcing. 


\section{Acknowledgements}

This work was supported by the Strategic Priority Research Program of the Chinese Academy of Sciences under Grant No. XDA20060102 and the International Partnership Program of Chinese Academy of Sciences under Grant No. 134111KYSB20160031. AGT was supported by the REAL Projections and EMERGENCE projects (NERC grant numbers NE/N018591/1 and NE/S004890/1 respectively). A. Dai was also supported by the National Science Foundation (OISE-1743738), and the U.S. National Oceanic and Atmospheric Administration (NA15OAR4310086 and NA18OAR4310425). RC, JM and JR were supported by the UK-China Research and Innovation Partnership Fund through the Met Office Climate Science for Service Partnership (CSSP) China as part of the Newton Fund. We acknowledge that the 57-member Earth system perturbed parameter ensemble (ESPPE) simulations with the HadCM3C model were run by Hugo Lambert and Ben Booth at the UK Met Office. The ESPPE data is available from the UK Met Office for non-commercial use. Requests for ESPPE data should be addressed to Dr. James M. Murphy (email: james.murphy@metoffice.gov.uk). The historical simulations of MPI-ESM ensemble were performed with the Swiss National Computing Centre (CSCS) and the corresponding RCP scenarios simulations were performed with the facilities at the German Climate Computing Centre (DKRZ). The MPI-ESM grand ensemble data is available for non-commercial use via https://esgf-data.dkrz.de/projects/mpige/. Detailed information of the data and references can be found from the website: https://www.mpimet.mpg.de/en/grand-ensemble/. The observational rainfall and surface temperature datasets are available on the Climate Data Guide website (https://climatedataguide.ucar.edu). The NCEP/NCAR reanalysis dataset can be obtained from https://www.esrl.noaa.gov/psd. The published PDO index of Mantua and Hare (2002) is available from the University of Washington, USA 
684 (http://www.jisao.washington.edu/pdo). The published TPI index of Henley et al. (2015) was accessed 685 at https://www.esrl.noaa.gov/psd/data/timeseries/IPOTPI. We also acknowledge the support from 686 Jiangsu Collaborative Innovation Center for Climate Change.

687 


\section{References}

Annamalai, H., K. Hamilton, and K. R. Sperber, 2007: The South Asian Summer Monsoon and Its Relationship with ENSO in the IPCC AR4 Simulations. Journal of Climate, 20, 1071-1092. doi:10.1175/jcli4035.1

Annamalai, H., J. Hafner, K. P. Sooraj, and P. Pillai, 2013: Global Warming Shifts the Monsoon Circulation, Drying South Asia. Journal of Climate, 26, 2701-2718. doi:10.1175/jcli-d-1200208.1

Bollasina, M. A., Y. Ming, and V. Ramaswamy, 2011: Anthropogenic aerosols and the weakening of the South Asian summer monsoon. Science, 334, 502-505. doi:10.1126/science.1204994

Chen, X. L., and T. J. Zhou, 2015: Distinct effects of global mean warming and regional sea surface warming pattern on projected uncertainty in the South Asian summer monsoon. Geophysical Research Letters, 42, 9433-9439. doi:10.1002/2015g1066384

Chiang, J. C. H., and A. H. Sobel, 2002: Tropical tropospheric temperature variations caused by ENSO and their influence on the remote tropical climate. Journal of Climate, 15, 2616-2631. doi:10.1175/1520-0442(2002)015<2616:tttvcb $>2.0$.co;2

Chou, C., and J. D. Neelin, 2004: Mechanisms of global warming impacts on regional tropical precipitation. Journal of Climate, 17, 2688-2701. doi:10.1175/15200442(2004)017<2688:mogwio>2.0.co;2

Chou, C., J. D. Neelin, C.-A. Chen, and J.-Y. Tu, 2009: Evaluating the "Rich-Get-Richer" Mechanism in Tropical Precipitation Change under Global Warming. Journal of Climate, 22, 1982-2005. doi:10.1175/2008jcli2471.1

Chou, C., D. Ryu, M. Lo, H. Wey, and H. Malano, 2018: Irrigation-induced land-atmosphere feedbacks and their impacts on Indian summer monsoon. Journal of Climate, 31, 8785-8801.

Collins, M., R. Knutti, J. Arblaster, J. L. Dufresne, T. Fichefet, P. Friedlingstein, et al., 2013: Longterm climate change: projections, commitments and irreversibility. In: Stocker, T. F., D. Qin, G. K. Plattner, M. Tignor, S. K. Allen, J. Boschung, et al., editors. Climate change 2013: The physical science basis. Cambridge: Contribution of working group I to the Fifth Assessment Report of the Intergovernmental Panel on Climate Change, pp. 1029-136.

Dai, A., and C. E. Bloecker, 2019: Impacts of internal variability on temperature and precipitation trends in large ensemble simulations by two climate models. Climate Dynamics, 52, 289-306.

Dai, A., J. C. Fyfe, S.-P. Xie, and X. Dai, 2015: Decadal modulation of global surface temperature by internal climate variability. Nature Climate Change, 5, 555-559. doi:10.1038/nclimate2605.

Dai, A., H. Li, Y. Sun, L. Hong, Linho, C. Chou, and T. Zhou, 2013: The relative roles of upper and lower tropospheric thermal contrasts and tropical influences in driving Asian summer monsoons. Journal of Geophysical Research, 118, 7024-7045.

Deser, C., R. Knutti, S. Solomon, and A. S. Phillips, 2012: Communication of the role of natural variability in future North American climate. Nature Climate Change, 2, 775-779. doi:10.1038/nclimate 1562 
Dong, B., and A. Dai, 2015: The influence of the Interdecadal Pacific Oscillation on Temperature and Precipitation over the Globe. Climate Dynamics, 45, 2667-2681. doi:10.1007/s00382-015$2500-\mathrm{x}$

Dong, B., A. Dai, M. Vuille, and O. Elison Timm, 2018: Asymmetric modulation of ENSO teleconnections by the Interdecadal Pacific Oscillation. J. Climate, 31:7337-7361. https://doi.org/10.1175/JCLI-D-17-0663.1.

Dong, L., and T. Zhou, 2014: The Indian Ocean Sea Surface Temperature Warming Simulated by CMIP5 Models during the Twentieth Century: Competing Forcing Roles of GHGs and Anthropogenic Aerosols. Journal of Climate, 27, 3348-3362. doi:10.1175/jcli-d-13-00396.1

Dong, L., T. Zhou, and X. Chen, 2014: Changes of Pacific decadal variability in the twentieth century driven by internal variability, greenhouse gases, and aerosols. Geophysical Research Letters, 41, 8570-8577. doi:10.1002/2014g1062269

Dong, L., T. Zhou, A. Dai, F. Song, B. Wu, and X. Chen, 2016: The Footprint of the Inter-decadal Pacific Oscillation in Indian Ocean Sea Surface Temperatures. Scientific Reports, 6. doi:10.1038/srep21251

Frankcombe, L. M., M. H. England, M. E. Mann, and B. A. Steinman, 2015: Separating Internal Variability from the Externally Forced Climate Response. Journal of Climate, 28, 8184-8202. doi:10.1175/jcli-d-15-0069.1

Gadgil, S., 2003: THE INDIAN MONSOON AND ITS VARIABILITY. Annual Review of Earth and Planetary Sciences, 31, 429-467.

Gill, A. E., 1980: Some simple solutions for heat - induced tropical circulation. Quarterly Journal of the Royal Meteorological Society, 106, 447-462.

Gordon, C., and Coauthors, 2000: The simulation of SST, sea ice extents and ocean heat transports in a version of the Hadley Centre coupled model without flux adjustments. Climate Dynamics, 16, 147-168. doi:10.1007/s003820050010

Goswami, B. N., and P. K. Xavier, 2005: ENSO control on the south Asian monsoon through the length of the rainy season. Geophysical Research Letters, 32. doi:10.1029/2005g1023216

Goswami, B. N., V. Venugopal, D. Sengupta, M. S. Madhusoodanan, and P. K. Xavier, 2006: Increasing trend of extreme rain events over India in a warming environment. Science, 314, 1442-1445. doi:10.1126/science.1132027

Guo, L., A. G. Turner, and E. J. Highwood, 2015: Impacts of 20th century aerosol emissions on the South Asian monsoon in the CMIP5 models. Atmospheric Chemistry and Physics, 15, 63676378. doi:10.5194/acp-15-6367-2015

Harris, I., P. D. Jones, T. J. Osborn, and D. H. Lister, 2014: Updated high-resolution grids of monthly climatic observations - the CRU TS3.10 Dataset. International Journal of Climatology, 34, 623642. doi:10.1002/joc.3711

Hawkins, E., and R. Sutton, 2009: The Potential to Narrow Uncertainty in Regional Climate Predictions. Bulletin of the American Meteorological Society, 90, 1095-1108. 
doi:10.1175/2009bams2607.1

- - 2010: The potential to narrow uncertainty in projections of regional precipitation change. Climate Dynamics, 37, 407-418. doi:10.1007/s00382-010-0810-6

Henley, B. J., J. Gergis, D. J. Karoly, S. Power, J. Kennedy, and C. K. Folland, 2015: A Tripole Index for the Interdecadal Pacific Oscillation. Climate Dynamics, 45, 3077-3090. doi:10.1007/s00382-015-2525-1

Hua, W., A. Dai, and M. Qin, 2018: Contributions of Internal Variability and External Forcing to the Recent Pacific Decadal Variations. Geophysical Research Letters, 45, 7084-7092. doi:10.1029/2018g1079033

Huang, X., T. Zhou, W. Zhang, J. Jiang, P. Li, and Y. Zhao, 2019: Northern Hemisphere land monsoon precipitation changes in the twentieth century revealed by multiple reanalysis datasets. Climate Dynamics, 1-19. doi: 10.1007/s00382-019-04982-z

Jiang, J., and T. Zhou, 2019: Global monsoon responses to decadal sea surface temperature variations during the 20th century: Evidence from AGCM simulations. Journal of Climate, online published. doi: 10.1175/JCLI-D-18-0890.1

Jiang, X., and M. Ting, 2017: A Dipole Pattern of Summertime Rainfall across the Indian Subcontinent and the Tibetan Plateau. Journal of Climate, 30, 9607-9620.

Jin, Q., and C. Wang, 2017: A revival of Indian summer monsoon rainfall since 2002. Nature Climate Change, 7, 587-594. doi:10.1038/nclimate3348

Jin, Q., Z.-L. Yang, and J. Wei, 2016: Seasonal Responses of Indian Summer Monsoon to Dust Aerosols in the Middle East, India, and China. Journal of Climate, 29, 6329-6349. doi:10.1175/jcli-d-15-0622.1

Jones, P. D., D. H. Lister, T. J. Osborn, C. Harpham, M. Salmon, and C. P. Morice, 2012: Hemispheric and large-scale land-surface air temperature variations: An extensive revision and an update to 2010. Journal of Geophysical Research-Atmospheres, 117. doi:10.1029/2011jd017139

Joshi, M. K., and F. Kucharski, 2017: Impact of Interdecadal Pacific Oscillation on Indian summer monsoon rainfall: an assessment from CMIP5 climate models. Climate Dynamics, 48, 23752391. doi:10.1007/s00382-016-3210-8

Joshi, M. K., and A. C. Pandey, 2011: Trend and spectral analysis of rainfall over India during 19012000. Journal of Geophysical Research, 116, D06104. doi: 10.1029/2010JD014966

Joshi, M. K., and A. Rai, 2015: Combined interplay of the Atlantic multidecadal oscillation and the interdecadal Pacific oscillation on rainfall and its extremes over Indian subcontinent. Climate Dynamics, 44, 3339-3359. doi: 10.1007/s00382-014-2333-z

Kalnay, E., and Coauthors, 1996: The NCEP/NCAR 40-year reanalysis project. Bulletin of the American Meteorological Society, 77, 437-471. doi:10.1175/15200477(1996)077<0437:tnyrp>2.0.co;2

Kendall, M., G. 1975: Rank Correlation Methods. 4th Edition, Charles Grifin, London. 
Kitoh, A., H. Endo, K. Krishna Kumar, I. F. A. Cavalcanti, P. Goswami, and T. Zhou, 2013: Monsoons in a changing world: A regional perspective in a global context. Journal of Geophysical Research: Atmospheres, 118, 3053-3065. doi:10.1002/jgrd.50258

Krishnamurthy, L., and V. Krishnamurthy, 2013: Influence of PDO on South Asian summer monsoon and monsoon-ENSO relation. Climate Dynamics, 42, 2397-2410. doi:10.1007/s00382-013$1856-\mathrm{Z}$

Krishnan, R., and M. Sugi, 2003: Pacific decadal oscillation and variability of the Indian summer monsoon rainfall. Climate Dynamics, 21, 233-242. doi:10.1007/s00382-003-0330-8

Lambert, F. H., G. R. Harris, M. Collins, J. M. Murphy, D. M. H. Sexton, and B. B. B. Booth, 2013: Interactions between perturbations to different Earth system components simulated by a fullycoupled climate model. Climate Dynamics, 41, 3055-3072. doi:10.1007/s00382-012-1618-3

Li, L., W. Li, and A. P. Barros, 2013: Atmospheric moisture budget and its regulation of the summer precipitation variability over the Southeastern United States. Climate Dynamics, 41, 613-631. doi:10.1007/s00382-013-1697-9

Li, X., M. Ting, C. Li, and N. Henderson, 2015: Mechanisms of Asian Summer Monsoon Changes in Response to Anthropogenic Forcing in CMIP5 Models. Journal of Climate, 28, 4107-4125. doi:10.1175/jcli-d-14-00559.1

Liu, H., T. Zhou, Y. Zhu, Y. Lin, 2012: The strengthening East Asia summer monsoon since the early 1990s. Chinese Science Bulletin, 57,1553-1558. doi:10.1007/s11434-012-4991-8

Maher, N., D. Matei, S. Milinski, and J. Marotzke, 2018: ENSO Change in Climate Projections: Forced Response or Internal Variability? Geophysical Research Letters, 45, 11390-11398. doi:10.1029/2018g1079764

Maher, N., and Coauthors, 2019: The Max Planck Institute Grand Ensemble-Enabling the Exploration of Climate System Variability. Journal of Advances in Modeling Earth Systems, 11, 2050-2069.

Mann, H. B., 1945: NONPARAMETRIC TESTS AGAINST TREND. Econometrica, 13, 245-259. doi: $10.2307 / 1907187$

Mantua, N. J., and S. R. Hare, 2002: The Pacific decadal oscillation. Journal of Oceanography, 58, 35 44. doi:10.1023/a:1015820616384

Matsuno, T., 1966: Quasi-Geostrophic Motions in the Equatorial Area. Journal of The Meteorological Society of Japan, 44, 25-43.

May, W., 2010: The sensitivity of the Indian summer monsoon to a global warming of $2^{\circ} \mathrm{C}$ with respect to pre-industrial times. Climate Dynamics, 37, 1843-1868. doi:10.1007/s00382-010-0942-8

Murphy, J. M., D. M. H. Sexton, D. N. Barnett, G. S. Jones, M. J. Webb, and D. A. Stainforth, 2004: Quantification of modelling uncertainties in a large ensemble of climate change simulations. Nature, 430, 768-772. doi:10.1038/nature02771

Murphy, J. M., B. B. Booth, C. A. Boulton, R. T. Clark, G. R. Harris, J. A. Lowe, and D. M. H. Sexton, 2014: Transient climate changes in a perturbed parameter ensemble of emissions-driven earth 
system model simulations. Climate Dynamics, 43, 2855-2885. doi:10.1007/s00382-014-20975

Parker, D. J., and Coauthors, 2016: The interaction of moist convection and mid-level dry air in the advance of the onset of the Indian monsoon. Quarterly Journal of the Royal Meteorological Society, 142, 2256-2272. doi:10.1002/qj.2815

Paul, S., S. Ghosh, R. Oglesby, A. Pathak, A. Chandrasekharan, and R. Ramsankaran, 2016: Weakening of Indian Summer Monsoon Rainfall due to Changes in Land Use Land Cover. Sci Rep, 6, 32177. doi:10.1038/srep32177

Rayner, N. A., and Coauthors, 2003: Global analyses of sea surface temperature, sea ice, and night marine air temperature since the late nineteenth century. Journal of Geophysical ResearchAtmospheres, 108. doi:10.1029/2002jd002670

Roxy, M. K., 2017: Land warming revives monsoon. Nature Climate Change, 7, 549-550. doi:10.1038/nclimate3356

Roxy, M. K., K. Ritika, P. Terray, R. Murtugudde, K. Ashok, and B. N. Goswami, 2015: Drying of Indian subcontinent by rapid Indian Ocean warming and a weakening land-sea thermal gradient. Nat Commun, 6, 7423. doi:10.1038/ncomms8423

Saha, A., S. Ghosh, A. S. Sahana, and E. P. Rao, 2014: Failure of CMIP5 climate models in simulating post-1950 decreasing trend of Indian monsoon. Geophysical Research Letters, 41, 7323-7330. doi:10.1002/2014g1061573

Salzmann, M., and R. Cherian, 2015: On the enhancement of the Indian summer monsoon drying by Pacific multidecadal variability during the latter half of the twentieth century. Journal of Geophysical Research: Atmospheres, 120, 9103-9118. doi:10.1002/2015jd023313

Salzmann, M., H. Weser, and R. Cherian, 2014: Robust response of Asian summer monsoon to anthropogenic aerosols in CMIP5 models. Journal of Geophysical Research: Atmospheres, 119, 11,321-311,337. doi:10.1002/2014jd021783

Schneider, U., A. Becker, P. Finger, A. Meyer-Christoffer, M. Ziese, and B. Rudolf, 2014: GPCC's new land surface precipitation climatology based on quality-controlled in situ data and its role in quantifying the global water cycle. Theoretical and Applied Climatology, 115, 15-40. doi:10.1007/s00704-013-0860-x

Seager, R., N. Naik, and G. A. Vecchi, 2010: Thermodynamic and Dynamic Mechanisms for LargeScale Changes in the Hydrological Cycle in Response to Global Warming. Journal of Climate, 23, 4651-4668. doi:10.1175/2010jcli3655.1

Singh, D., S. Ghosh, M. K. Roxy, and S. McDermid, 2019: Indian summer monsoon: Extreme events, historical changes, and role of anthropogenic forcings. Wiley Interdisciplinary ReviewsClimate Change, 10. doi:10.1002/wcc.571

Taylor, K. E., R. J. Stouffer, and G. A. Meehl, 2012: AN OVERVIEW OF CMIP5 AND THE EXPERIMENT DESIGN. Bulletin of the American Meteorological Society, 93, 485-498. doi:10.1175/bams-d-11-00094.1 
Turner, A. G., and H. Annamalai, 2012: Climate change and the South Asian summer monsoon. Nature Climate Change, 2, 587-595. doi:10.1038/nclimate1495

Wang, B., J. Liu, H. J. Kim, P. J. Webster, S. Y. Yim, and B. Xiang, 2013: Northern Hemisphere summer monsoon intensified by mega-El Nino/southern oscillation and Atlantic multidecadal oscillation. Proc Natl Acad Sci U S A, 110, 5347-5352. doi:10.1073/pnas.1219405110

Wang, P. X., B. Wang, H. Cheng, J. Fasullo, Z. Guo, T. Kiefer, and Z. Liu, 2017: The global monsoon across time scales: Mechanisms and outstanding issues. Earth-Science Reviews, 174, 84-121. doi:10.1016/j.earscirev.2017.07.006

Webster, P. J., and S. Yang, 1992: MONSOON AND ENSO - SELECTIVELY INTERACTIVE SYSTEMS. Quarterly Journal of the Royal Meteorological Society, 118, 877-926. doi:10.1002/qj.49711850705

Willmott, C. J., and K. Matsuura, 2000: Terrestrial air temperature and precipitation: Monthly and annual climatologies. Centre for Climate Research, Department of Geography, University of Delaware.

http://climate.geog.udel.edu/ climate/html_pages/Global2_Clim/README.global2_clim.ht $\mathrm{ml}$.

Xavier, P. K., C. Marzin, and B. N. Goswami, 2007: An objective definition of the Indian summer monsoon season and a new perspective on the ENSO-monsoon relationship. Quarterly Journal of the Royal Meteorological Society, 133, 749-764. doi:10.1002/qj.45

Xie, S. P., C. Deser, G. A. Vecchi, J. Ma, H. Teng, and A. T. Wittenberg, 2010: Global warming pattern formation: Sea surface temperature and rainfall. J. Clim., 23, 966-986, doi:10.1175/2009JCLI3329.1. 


\section{Figures Caption List}

899

900

901

902

903

904

905

906

907

908

909

910

911

912

913

914

915

916

917

918

919

920

921

922

923

924

925

926

Fig. 1. Evaluation of the ESPPE and MPI-ESM in simulating climatological June-July-August (JJA) Indian summer monsoon (ISM) rainfall and its relation to IPO. (a) CRU, (c) GPCC, (e) UDel, (g) ESPPE ensemble mean and (i) MPI-ESM ensemble mean (EM) climatological JJA mean rainfall over ISM region in 1950-2013. Regressed 9-year running mean JJA rainfall with respect to the observed IPO index during 1950-2013: (b) CRU, (d) GPCC and (f) UDel. (d) ESPPE and (f) MPI-ESM EM of the regressed internal component of JJA 9-year running mean rainfall onto the IPO index within each ensemble member during 1950-2013. Stippling denotes 4 of 5 ensemble members agreeing on the sign of change. Units: $\mathrm{mm}_{\text {day }}{ }^{-1}$.

Fig. 2. Regressed 9-year running-mean JJA SST anomalies from HadISST (units: K) with respect to standardized 9year running-mean (a) PDO index, (b) TPI index and (c) IPO index during the period of 1920-2013. (d) ESPPE EM of regressed 9-year running mean JJA SST with respect to standardized IPO index within each member during the period of 1920-2013. Slant hatching denotes regional signals significant at the $95 \%$ confidence level. Stippling denotes 4 of the 5 ensemble members in agreement on the sign of change. (e) Standardized time series of observed IPO index (defined as 9-year running-mean SST gradients between TCEP and NP, positive in red and negative in blue), standardized 9-year running-mean PDO (orange) and TPI (grey) index. The correlation coefficients between the IPO and PDO or TPI indexes are 0.93 and $0.89(p<0.01)$, respectively, during the historical period of 19202013. (f) Time series of IPO index from different ESPPE members. Black, brown and blue lines denote the IPO indices derived from HadISST observations and the 10 members with the strongest positive (Pos10) and the strongest negative (Neg10) transitions, respectively. The 10 members are chosen separately for both periods of 1950-1999 and 1999-2013. Light brown and blue shadings show the spread among the 10 members.

Fig. 3. Spatial patterns of 9-year running-mean JJA rainfall trends during the period of 1950-1999 derived from the (a) CRU, (b) GPCC, (c) UDel, (g) the average OBS and (h) the ESPPE EM. (i) The standard deviation (STD) of the rainfall trends among the 57 ESPPE members for 1950-1999. (d, e, f, j, k, l) are same as (a, b, c, g, h, i) but for 19992013. Units: $\mathrm{mm} \mathrm{day}^{-1} \mathrm{decade}^{-1}$. Slant hatching denotes rainfall trends significant at the $95 \%$ confidence level. (m-n) 
Time series of the 9-year running-mean JJA rainfall anomalies relative to 1950-2013 mean average over north-central India (NCI; $\left.20^{\circ} \mathrm{N}-28^{\circ} \mathrm{N}, 76^{\circ} \mathrm{E}-87^{\circ} \mathrm{E}\right)$ outlined by the rectangle in (a-1). Units: $\mathrm{mm}$ day ${ }^{-1}$. In (m), colours of orange, purple, green and black represent the CRU, GPCC, UDel datasets and their average (referred to as OBS), respectively. The coloured numbers in $(\mathrm{m})$ denote the NCI rainfall trends of corresponding datasets during both periods. In (n), black is for the OBS. Red line and shading denote the EM and $5^{\text {th }}$ and $95^{\text {th }}$ percentile of the 57 members. Brown and blue solid lines represent the mean of 10 members with strongest positive (Pos10) and the strongest negative (Neg10) IPO transitions during 1950-1999 and 1999-2013, respectively. Brown and blue dashed lines represent the mean difference of the Pos10 minus EM during 1950-1999 and the Neg10 minus EM during 1999-2013.

Fig. 4. Moisture budget analysis of the external forced rainfall trend derived from the ESPPE EM. (a). Moisture budget analysis on EM NCI rainfall trend (dots denote trend differences significant at 95\% confidence level) during 1950-1999 (dark color bars) and 1999-2013 (light color bars). Rainfall change is balanced by the changes of evaporation, dynamic and thermodynamic components and a nonlinear term (blue and light blue bars). The dynamic component is further separated into vertical, zonal and meridional dynamic components of moisture convergence (red and pink bars). (b, d, f, h) are spatial patterns of EM trend during 1950-1999 of dynamic component, thermodynamic component, vertical dynamic component and zonal dynamic component of moisture advection, respectively. (c, e, g, i) are same as (b, d, f, h) but for 1999-2013. Units: mm day ${ }^{-1}$ decade $^{-1}$. Slant hatching denotes regions significant at $95 \%$ confidence level.

Fig. 5. (a) Trend of EM JJA 850hPa specific humidity (shading, units: $\mathrm{g} \mathrm{kg}^{-1}$ decade$^{-1}$ ) and EM climatological $850 \mathrm{hPa}$ winds (vectors, units: $\mathrm{m} \mathrm{s}^{-1}$ ) from 1950-1999. (c) EM climatological JJA 850hPa specific humidity (shading, units: g $\mathrm{kg}^{-1}$ ) and trend of EM rainfall (contours, positive in solid blue lines and negative in dashed brown lines; units: mm day $^{-1}$ decade $^{-1}$ ) and 850hPa winds (vectors, units: $\mathrm{m} \mathrm{s}^{-1}$ decade $^{-1}$ ) from 1950-1999. (e) Trend of EM JJA near surface temperature and SST (shading, units: $\mathrm{K} \mathrm{decade}^{-1}$ ) and sea level pressure (contours, positive in solid purple lines and negative in dashed cyan lines; units: $\mathrm{Pa}$ decade $\left.^{-1}\right)$. (g) Cross section of zonally-averaged $\left(65^{\circ} \mathrm{E}-95^{\circ} \mathrm{E}\right)$ trend of $\mathrm{EM}$ air temperature (shading, units: $\mathrm{K}$ decade $^{-1}$ ) and winds (vectors, meridional and vertical components; units: $\mathrm{m} \mathrm{s}^{-1}$ decade $^{-1}$ ). The vertical component is calculated with a scale factor of -100 to allow the vertical pressure-velocity to 
be comparable with the meridional component. (b, d, f, h) are same as (a, c, e, g) but for 1999-2013. Slant hatching denotes regions significant at $95 \%$ confidence level.

Fig. 6. Histograms of spread in NCI rainfall trends among 57 members during (a) 1950-1999 and (b) 1999-2013 (grey, yellow and blue bars denote the trends of the original rainfall, the internal component and the uncertain-forced component of rainfall). Correlation between trends of the original rainfall (x-bar, units: mm day ${ }^{-1}$ decade $\left.^{-1}\right)$ and the internal component of the rainfall (y-bar, units: $\mathrm{mm} \mathrm{day}^{-1}$ decade $^{-1}$ ) over the NCI region derived from ESPPE members (number indicated in the circle) during the period (c) 1950-1999 and (d) 1999-2013. (The outlined member "37" in c. is caused by the combination of a positive internal rainfall trend and an evidently positive forced trend.) Brown circles in (c) denote the 10 members with the strongest positive IPO phase transition during 1950-1999. Blue circles in (d) denote the 10 members with the strongest negative IPO phase transition during 1999-2013. The regression pattern of the internal SST trends with respect to the NCI rainfall trends across 57 members through the member index: (e) 1950-1999 and (f) 1999-2013 (units: K (decade) ${ }^{-1}$ ). Slant hatching denotes regions significant at the $95 \%$ confidence level. The rectangles in (e-f) outline the tropical central-eastern Pacific $\left(\mathrm{TCEP}, 170^{\circ} \mathrm{W}-90^{\circ} \mathrm{W}\right.$, $\left.10^{\circ} \mathrm{S}-10^{\circ} \mathrm{N}\right)$ and the North Pacific (NP, $\left.150^{\circ} \mathrm{E}-150^{\circ} \mathrm{W}, 25^{\circ} \mathrm{N}-45^{\circ} \mathrm{N}\right)$.

Fig. 7. Moisture budget analysis of the rainfall trend related to IPO phase transitions. (a). Moisture budget analysis on NCI rainfall trend difference between the 10 members with the strongest positive IPO phase transition and ensemble mean during 1950-1999 (Pos10-EM; dark colour bars). Light colour bars are for Neg10-EM during 19992013. Dots denote trend differences significant at $95 \%$ confidence level. Rainfall change is balanced by the changes of evaporation, dynamic and thermodynamic components and a nonlinear term (blue and light blue bars). The dynamic component is further separated into vertical, zonal and meridional dynamic components of moisture advection (red and pink bars). (b, d, f, h) are spatial patterns of Pos10-EM trend during 1950-1999 of rainfall, dynamic component, vertical dynamic component and zonal dynamic component of moisture advection, respectively. (c, e, g, i) are same as (b, d, f, h) but for Neg10-EM during 1999-2013. Units: mm day ${ }^{-1}$ decade $^{-1}$. Slant hatching denotes regions significant at 95\% confidence level. 
Fig. 8. Mechanisms of IPO's modulation of ISM rainfall reduction and revival. JJA trend differences between the 10 members with the strongest positive IPO phase transition and ensemble mean (Pos10-EM) from 1950-1999 for: (a) velocity potential (shading, units: $\mathrm{m}^{2} \mathrm{~s}^{-1}$ decade $^{-1}$ ) and divergent winds (vectors, units: $\mathrm{m} \mathrm{s}^{-1} \mathrm{decade}^{-1}$ ) at 200hPa; (c) rainfall (shading, units: $\mathrm{mm} \mathrm{day}^{-1}$ decade $^{-1}$ ) and $850 \mathrm{hPa}$ stream function anomalies (contours, units: $10^{6} \mathrm{~m}^{2} \mathrm{~s}^{-1} \mathrm{decade}^{-}$ ${ }^{1}$ ); (e) $850 \mathrm{hPa}$ winds (vectors, units: $\mathrm{m} \mathrm{s}^{-1}$ decade $^{-1}$ ) and climatological specific humidity (shading, units: g/kg). (b), (d) and (f) are the same as (a), (c) and (e) but for Neg10-EM trend differences in 1999-2013. Slant hatching denotes regions significant at $95 \%$ confidence level.

Fig. 9. JJA surface temperature trend related to IPO phase transitions. (a) Spatial patterns of the trend differences of the JJA surface temperature between the 10 members with the strongest positive IPO phase transition and ensemble mean (Pos10-EM) during 1950-1999. (b) is the same as (a) but for trend differences of Neg10-EM during 1999-2013. (c) Composite 9-year running mean anomalies (relative to 1950-2013 mean) derived from the Pos10-EM composite difference for 1950-1999 and the Neg10-EM composite difference for 1999-2013 for surface air temperature over the landmass north of India (red, land area in $30^{\circ} \mathrm{N}-45^{\circ} \mathrm{N}, 65^{\circ} \mathrm{E}-90^{\circ} \mathrm{E}$ ), SST over the tropical Indian Ocean (blue, ocean area over the $10^{\circ} \mathrm{S}-25^{\circ} \mathrm{N}, 40^{\circ} \mathrm{E}-100^{\circ} \mathrm{E}$ ) and the land-sea thermal contrast (black, i.e., the difference between the red and blue lines). The purple line denotes the observed land-sea surface thermal contrast derived from the CRUTEM4 and HadISST datasets.

1004

1005

Fig. 10. JJA mid-upper tropospheric thickness trend related to IPO phase transitions. (a) Spatial patterns of the trend 1007 differences of the JJA 500-200hPa tropospheric thickness between the 10 members with the strongest positive and the ensemble mean (Pos10-EM) during 1950-1999. (b) is the same as (a) but for trend differences of Neg10-EM during 1999-2013. (c) Composite 9-year running mean anomalies (relative to 1950-2013 mean) derived from the Pos10-EM composite difference for 1950-1999 and the Neg10-EM composite difference for 1999-2013 for 500$200 \mathrm{hPa}$ tropospheric thickness over Eurasia (brown, the northern box over $25^{\circ} \mathrm{N}-45^{\circ} \mathrm{N}, 60^{\circ} \mathrm{E}-100^{\circ} \mathrm{E}$ in $\mathrm{a}-\mathrm{b}$ ), the 
tropical Indian Ocean (green, the southern box over $10^{\circ} \mathrm{S}-10^{\circ} \mathrm{N}, 60^{\circ} \mathrm{E}-100^{\circ} \mathrm{E}$ in a-b) and the meridional thermal gradient over India (black, i.e., the difference between the brown and green lines). The purple line denotes the meridional 500-200hPa tropospheric thickness gradient derived from the NCEP/NCAR reanalysis.

Fig. 11. Adjustments of the ISM rainfall trends according to the IPO phase transition. (a) EM of the IPO-adjusted internal JJA rainfall trends $\left(\partial_{t} p r_{\text {internal_adj }}\right)$ in ESPPE during 1950-1999, representing the rainfall trend caused by the observed IPO phase transition. (b) EM of the IPO-adjusted total JJA rainfall trends $\left(\partial_{t} p r_{a d j}\right)$ in ESPPE during 1950-1999, representing the rainfall trend caused by both the external forcing and the observed IPO. (c) Histograms (bars) and fitted distribution with 100 bins (lines) of the area-averaged rainfall trends over the NCI region during 1950-1999 derived from the 57 ESPPE members. The blue bars and the fitted blue curves show the frequency of occurrence of the original rainfall trends, with the blue dot and horizontal blue line denote the EM and STD of $0.01 \pm$ 0.14. The red bars and the fitted red curves show the frequency of occurrence of the rainfall trends with adjustments accounting for the influence of the observational IPO phase transition (red dot and horizontal red line denote the EM and STD of $-0.15 \pm 0.13$. (d-f) are same as (a-c) but for 1999-2013. The EM and STD for the blue and red bars in (f) are $0.42 \pm 0.61$ and $0.68 \pm 0.54$, respectively. The black dashed lines in (c) and (f) denote the observed NCI rainfall trends of -0.11 and 0.66 , respectively. Units: $\mathrm{mm}^{\mathrm{day}}{ }^{-1} \mathrm{decade}^{-1}$.

Fig. 12. Spatial patterns of 9-year running-mean JJA rainfall trends during the period of (a) 1950-1999 and (b) 19992013 derived from the EM of the 100-member MPI-ESM ensemble. The STD of the rainfall trends among the 100 MPI-ESM members for (c) 1950-1999 and (d) 1999-2013. Rainfall trends derived from (e) the 10 members with the strongest positive IPO phase transition (Pos10) during 1950-1999, (f) the 10 members with the strongest negative IPO phase transition (Neg10) during 1999-2013. Units: mm day ${ }^{-1}$ decade $^{-1}$. Slant hatching denotes trends significant at the $95 \%$ confidence level. (g) Time series of the 9-year running-mean of JJA rainfall anomalies averaged over NCI. Units: $\mathrm{mm}$ day ${ }^{-1}$. Black is for the OBS. Red line and shading denote the EM and $5^{\text {th }}$ and $95^{\text {th }}$ percentile of the 100 members. Brown and blue solid lines represent the mean of Pos10 and Neg10 members during 1950-1999 and 19992013, respectively. Brown and blue dashed lines represent the mean difference of the Pos10 minus EM during 1950- 
Fig. 13. The regression pattern of the internal SST trends with respect to the NCI rainfall trends across 100 members 1044 through the member index: (a) 1950-1999 and (b) 1999-2013 (units: K (decade) ${ }^{-1}$ ). Slant hatching denotes regions 1045 significant at the $95 \%$ confidence level. (c) EM of the IPO-adjusted internal JJA rainfall trends ( $\left.\partial_{t} p r_{\text {internal_adj }}\right)$ in MPI-ESM during 1950-1999, representing the rainfall trend caused by the observed IPO phase transition. (d) EM of the IPO-adjusted total JJA rainfall trends $\left(\partial_{t} p r_{a d j}\right)$ in MPI-ESM during 1950-1999, representing the rainfall trend caused by both the external forcing and the observed IPO. (e-f) are same as (c-d) but for 1999-2013. Units: mm day 1049 ${ }^{1}$ decade $^{-1}$

1050

1051

1052

Fig. 14. Schematic diagrams showing how external forcing and internal variability affect the recent decline and 1053 recovery of ISM rainfall, respectively.

1054

1055 


\section{Figures}
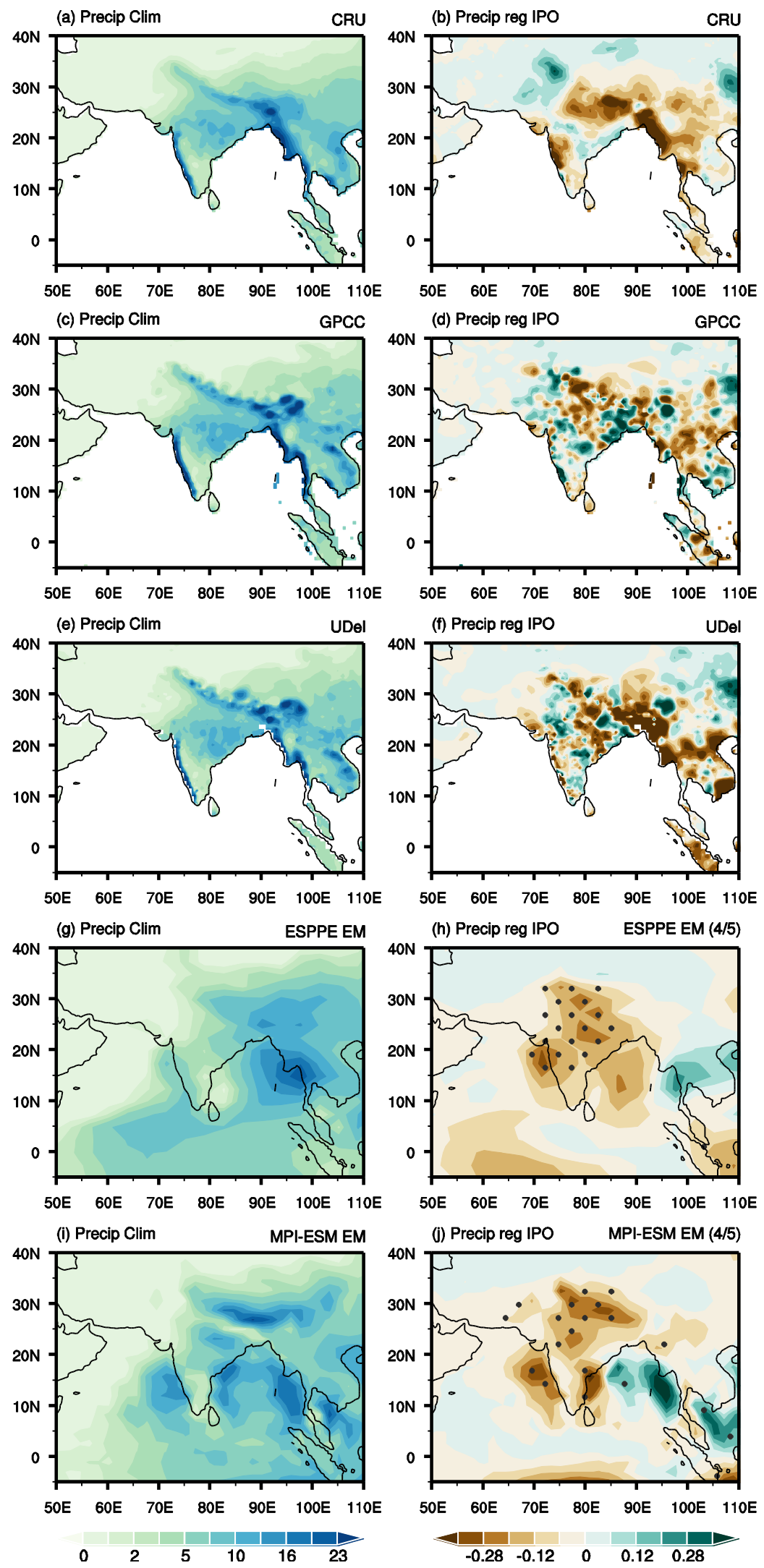
1058 Fig. 1. Evaluation of the ESPPE and MPI-ESM in simulating climatological June-July-August (JJA) Indian summer 1059 monsoon (ISM) rainfall and its relation to IPO. (a) CRU, (c) GPCC, (e) UDel, (g) ESPPE ensemble mean and (i) 1060 MPI-ESM ensemble mean (EM) climatological JJA mean rainfall over ISM region in 1950-2013. Regressed 9-year 1061 running mean JJA rainfall with respect to the observed IPO index during 1950-2013: (b) CRU, (d) GPCC and 1062 (f) UDel. (d) ESPPE and (f) MPI-ESM EM of the regressed internal component of JJA 9-year running mean 1063 rainfall onto the IPO index within each ensemble member during 1950-2013. Stippling denotes 4 of 5 ensemble 1064 members agreeing on the sign of change. Units: $\mathrm{mm}_{\text {day }}{ }^{-1}$.

1065 
(a) SST reg PDO

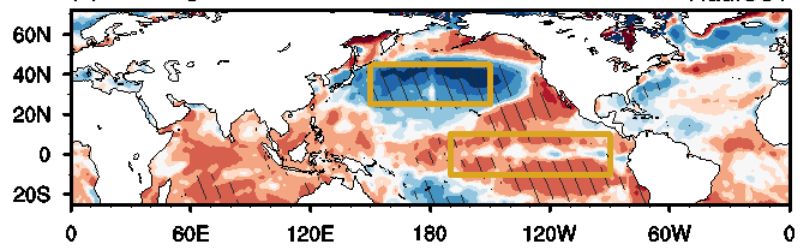

(c) SST reg IPO

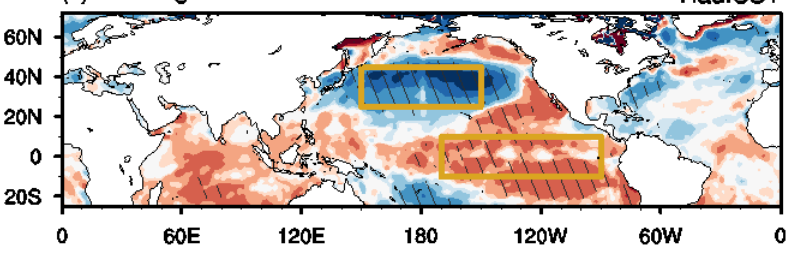

(b) SST reg TPI

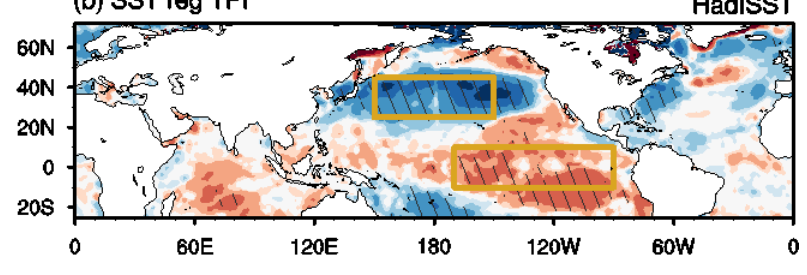

(d) SST reg IPO

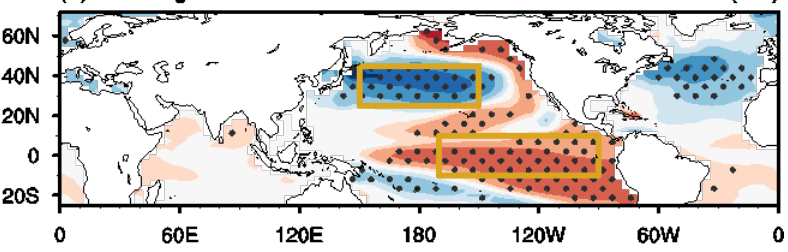

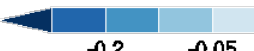

$\subset C=0.93,0.89$

(e) Standardized IPO \& PDO \& TPI Index

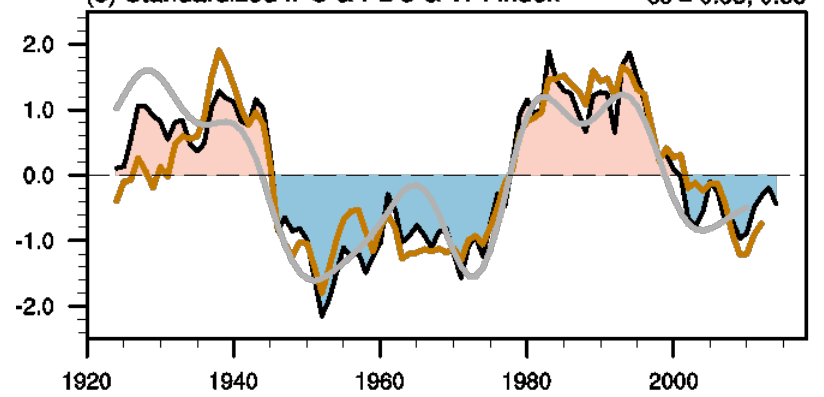

(f) Time Series of IPO Index

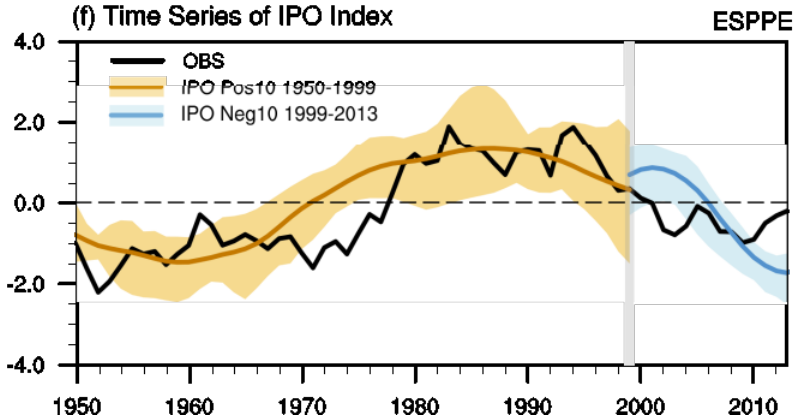

1068

1069

1070

1071

1072

1073

1074

1075

1076

1077

1078

1079

1080

Fig. 2. Regressed 9-year running-mean JJA SST anomalies from HadISST (units: K) with respect to standardized 9year running-mean (a) PDO index, (b) TPI index and (c) IPO index during the period of 1920-2013. (d) ESPPE EM of regressed 9-year running mean JJA SST with respect to standardized IPO index within each member during the period of 1920-2013. Slant hatching denotes regional signals significant at the $95 \%$ confidence level. Stippling denotes 4 of the 5 ensemble members in agreement on the sign of change. (e) Standardized time series of observed IPO index (defined as 9-year running-mean SST gradients between TCEP and NP, positive in red and negative in blue), standardized 9-year running-mean PDO (orange) and TPI (grey) index. The correlation coefficients between the IPO and PDO or TPI indexes are 0.93 and $0.89(p<0.01)$, respectively, during the historical period of 19202013. (f) Time series of IPO index from different ESPPE members. Black, brown and blue lines denote the IPO indices derived from HadISST observations and the 10 members with the strongest positive (Pos 10) and the strongest negative (Neg10) transitions, respectively. The 10 members are chosen separately for both periods of 1950-1999 and 1999-2013. Light brown and blue shadings show the spread among the 10 members. 

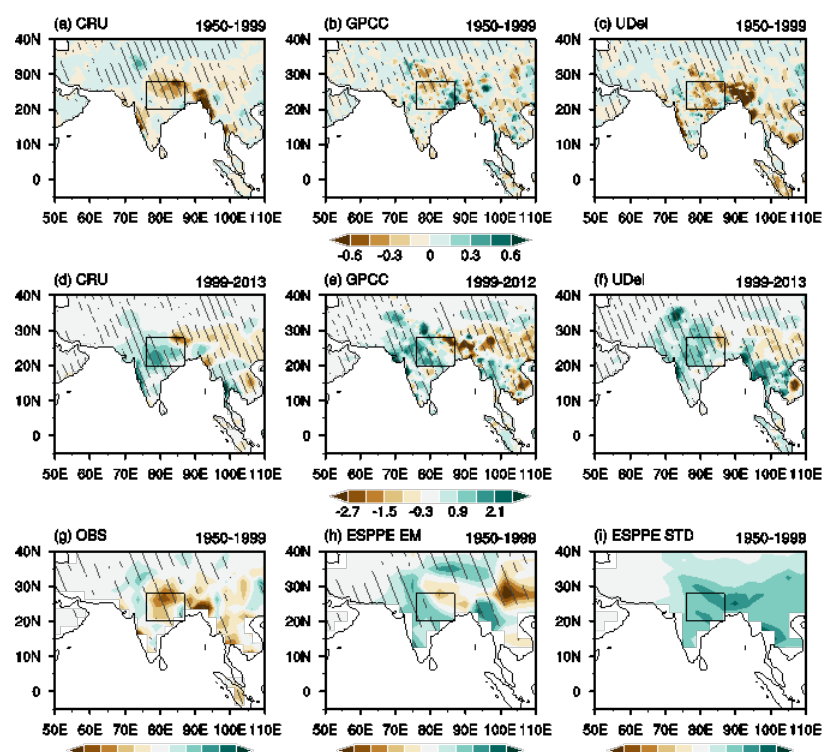

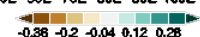

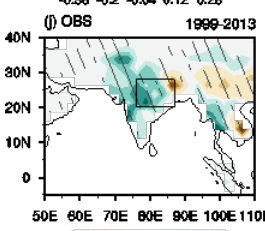
OE TOE QOE QOE TOOE
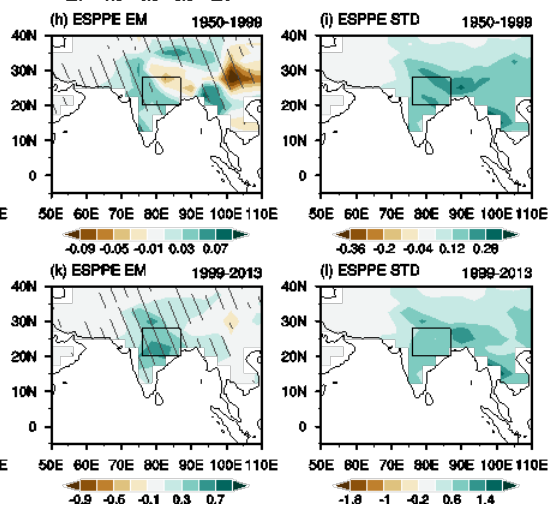

(m) Time Series of NCl Precip
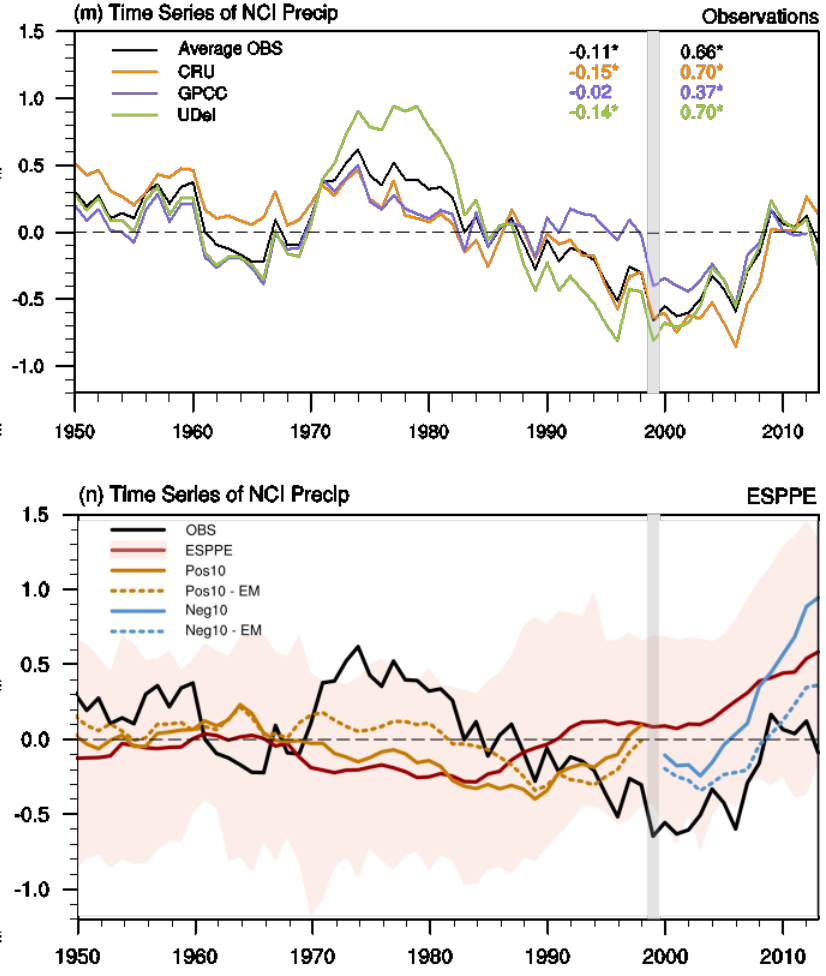

Fig. 3. Spatial patterns of 9-year running-mean JJA rainfall trends during the period of 1950-1999 derived from the (a) CRU, (b) GPCC, (c) UDel, (g) the average OBS and (h) the ESPPE EM. (i) The standard deviation (STD) of the rainfall trends among the 57 ESPPE members for 1950-1999. (d, e, f, j, k, l) are same as (a, b, c, g, h, i) but for 19992013. Units: $\mathrm{mm}_{\text {day }}{ }^{-1}$ decade $^{-1}$. Slant hatching denotes rainfall trends significant at the $95 \%$ confidence level. (m-n) Time series of the 9-year running-mean JJA rainfall anomalies relative to 1950-2013 mean average over north-central India (NCI; $20^{\circ} \mathrm{N}-28^{\circ} \mathrm{N}, 76^{\circ} \mathrm{E}-87^{\circ} \mathrm{E}$ ) outlined by the rectangle in (a-1). Units: $\mathrm{mm}$ day ${ }^{-1}$. In (m), colours of orange, purple, green and black represent the CRU, GPCC, UDel datasets and their average (referred to as OBS), respectively. The coloured numbers in (m) denote the NCI rainfall trends of corresponding datasets during both periods. In (n), black is for the OBS. Red line and shading denote the EM and $5^{\text {th }}$ and $95^{\text {th }}$ percentile of the 57 members. Brown and blue solid lines represent the mean of 10 members with strongest positive (Pos10) and the strongest negative (Neg10) IPO transitions during 1950-1999 and 1999-2013, respectively. Brown and blue dashed lines represent the mean difference of the Pos10 minus EM during 1950-1999 and the Neg10 minus EM during 1999-2013. 


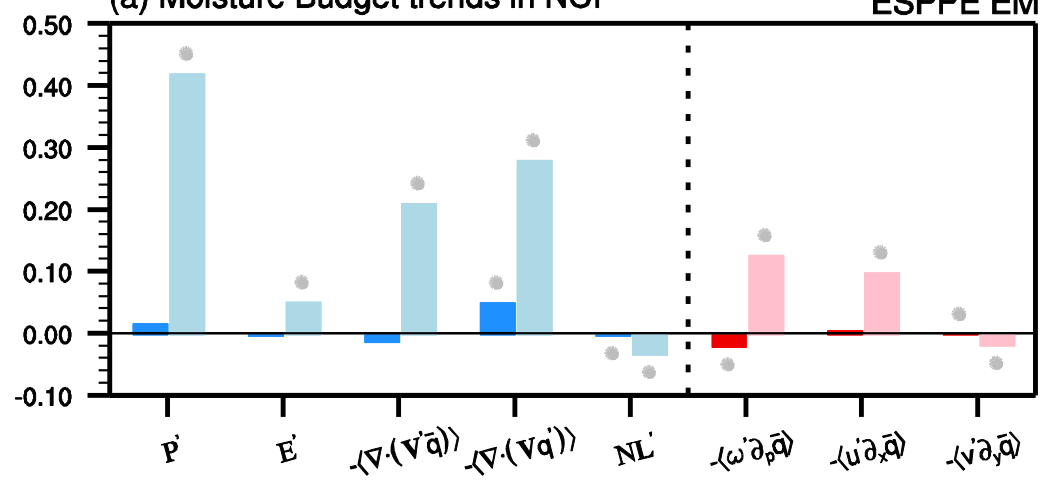

(b) $-\left\langle\nabla \cdot\left(\mathbf{V}^{\prime} \overline{\mathbf{q}}\right)\right\rangle$

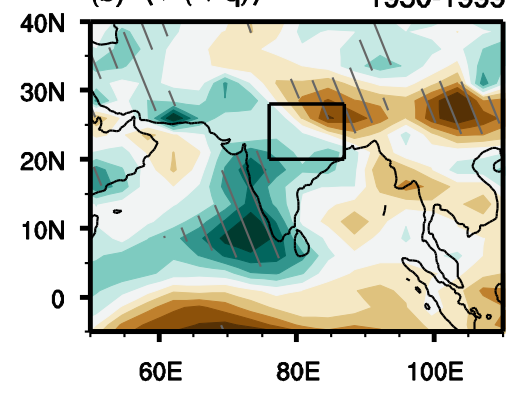

(d) $-\left\langle\nabla \cdot\left(\mathbf{V} \mathbf{q}^{\prime}\right)\right\rangle$

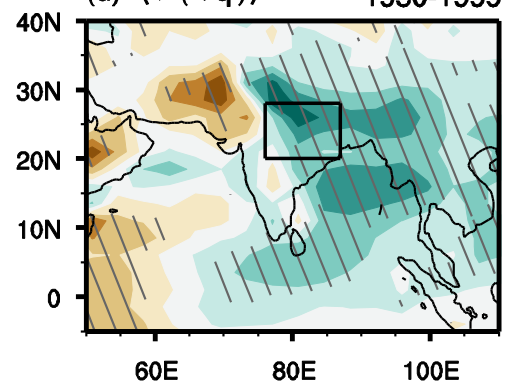

(f) $-\left\langle\omega^{\prime} \partial_{\mathrm{p}} \overline{\mathrm{q}}\right\rangle \quad 1950-1999$

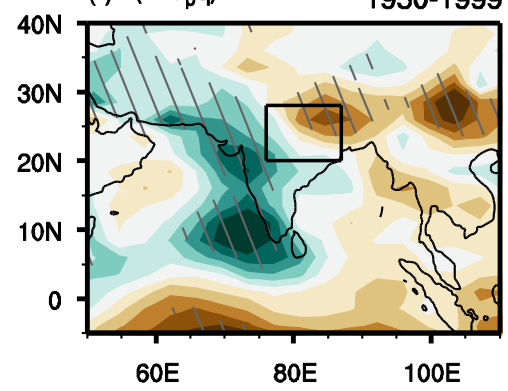

(h) $-\left\langle u^{\prime} \partial_{x} \bar{a}\right\rangle \quad 1950-1999$

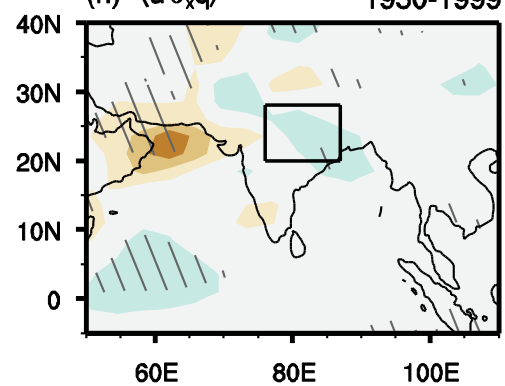

60E $\quad 80 \mathrm{E} \quad 100 \mathrm{E}$ (c) $-\left\langle\nabla \cdot\left(\mathbf{V}^{\prime} \overline{\mathbf{q}}\right)\right\rangle$

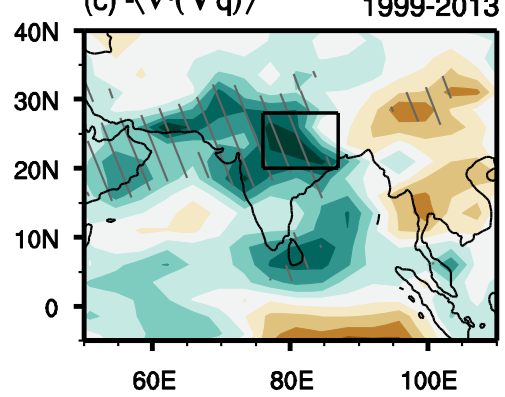

(e) $-\left\langle\nabla \cdot\left(\mathbf{V} \mathbf{q}^{\prime}\right)\right\rangle$

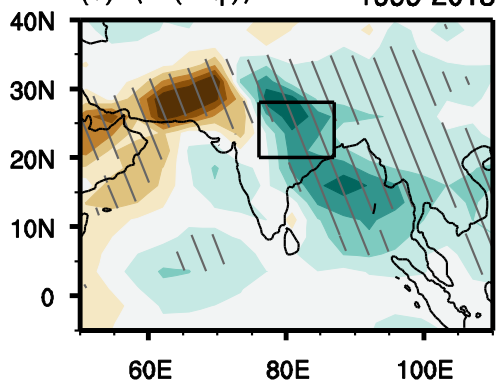

(g) $-\left\langle\omega^{\prime} \partial_{\mathrm{p}} \overline{\mathrm{q}}\right\rangle$

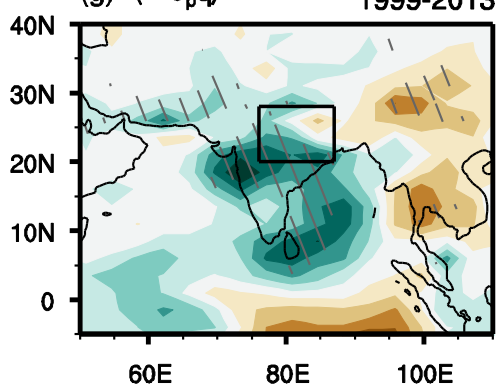

(i) $-\left\langle u^{\prime} \partial_{x} \bar{a}\right\rangle \quad 1999-2013$

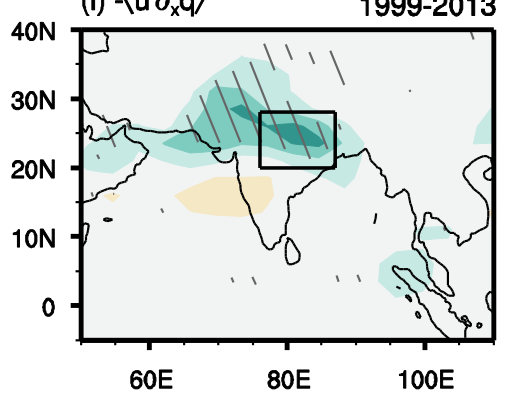

$\begin{array}{llllll} & & & & & \\ & -54 & -0.3 & -0.06 & 0.18 & 0.42\end{array}$ 
1096 Fig. 4. Moisture budget analysis of the external forced rainfall trend derived from the ESPPE EM. (a). Moisture 1097 budget analysis on EM NCI rainfall trend (dots denote trend differences significant at 95\% confidence level) during 1098 1950-1999 (dark color bars) and 1999-2013 (light color bars). Rainfall change is balanced by the changes of 1099 evaporation, dynamic and thermodynamic components and a nonlinear term (blue and light blue bars). The dynamic 1100 component is further separated into vertical, zonal and meridional dynamic components of moisture convergence 1101 (red and pink bars). (b, d, f, h) are spatial patterns of EM trend during 1950-1999 of dynamic component, 1102 thermodynamic component, vertical dynamic component and zonal dynamic component of moisture advection, 1103 respectively. (c, e, g, i) are same as (b, d, f, h) but for 1999-2013. Units: mm day ${ }^{-1}$ decade $^{-1}$. Slant hatching denotes 1104 regions significant at $95 \%$ confidence level. 

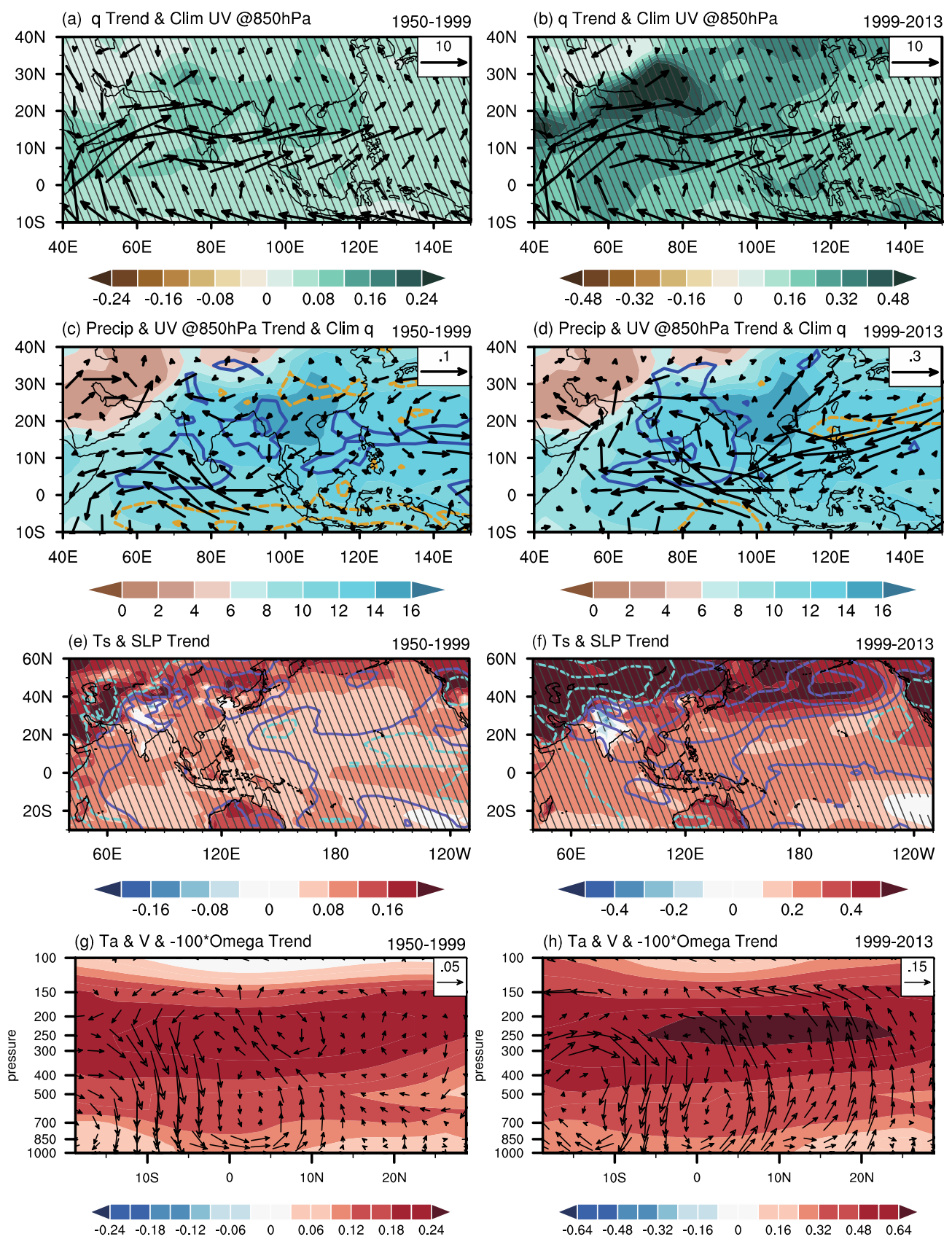

1107 Fig. 5. (a) Trend of EM JJA 850hPa specific humidity (shading, units: $\mathrm{g} \mathrm{kg}^{-1} \mathrm{decade}^{-1}$ ) and EM climatological 850hPa winds (vectors, units: $\mathrm{m} \mathrm{s}^{-1}$ ) from 1950-1999. (c) EM climatological JJA 850hPa specific humidity (shading, units: $\mathrm{g}$ $\mathrm{kg}^{-1}$ ) and trend of EM rainfall (contours, positive in solid blue lines and negative in dashed brown lines; units: mm day $^{-1}$ decade $^{-1}$ ) and $850 \mathrm{hPa}$ winds (vectors, units: $\mathrm{m} \mathrm{s}^{-1}$ decade $^{-1}$ ) from 1950-1999. (e) Trend of EM JJA near surface temperature and SST (shading, units: $\mathrm{K}_{\text {decade }}{ }^{-1}$ ) and sea level pressure (contours, positive in solid purple lines and negative in dashed cyan lines; units: Pa decade $\left.{ }^{-1}\right)$. (g) Cross section of zonally-averaged $\left(65^{\circ} \mathrm{E}-95^{\circ} \mathrm{E}\right)$ trend of EM air temperature (shading, units: $\mathrm{K}_{\text {decade }}{ }^{-1}$ ) and winds (vectors, meridional and vertical components; units: $\mathrm{m} \mathrm{s}^{-1}$ decade $\left.^{-1}\right)$. The vertical component is calculated with a scale factor of -100 to allow the vertical pressure-velocity to 
1115 be comparable with the meridional component. (b, d, f, h) are same as (a, c, e, g) but for 1999-2013. Slant hatching 1116 denotes regions significant at $95 \%$ confidence level.

1117 

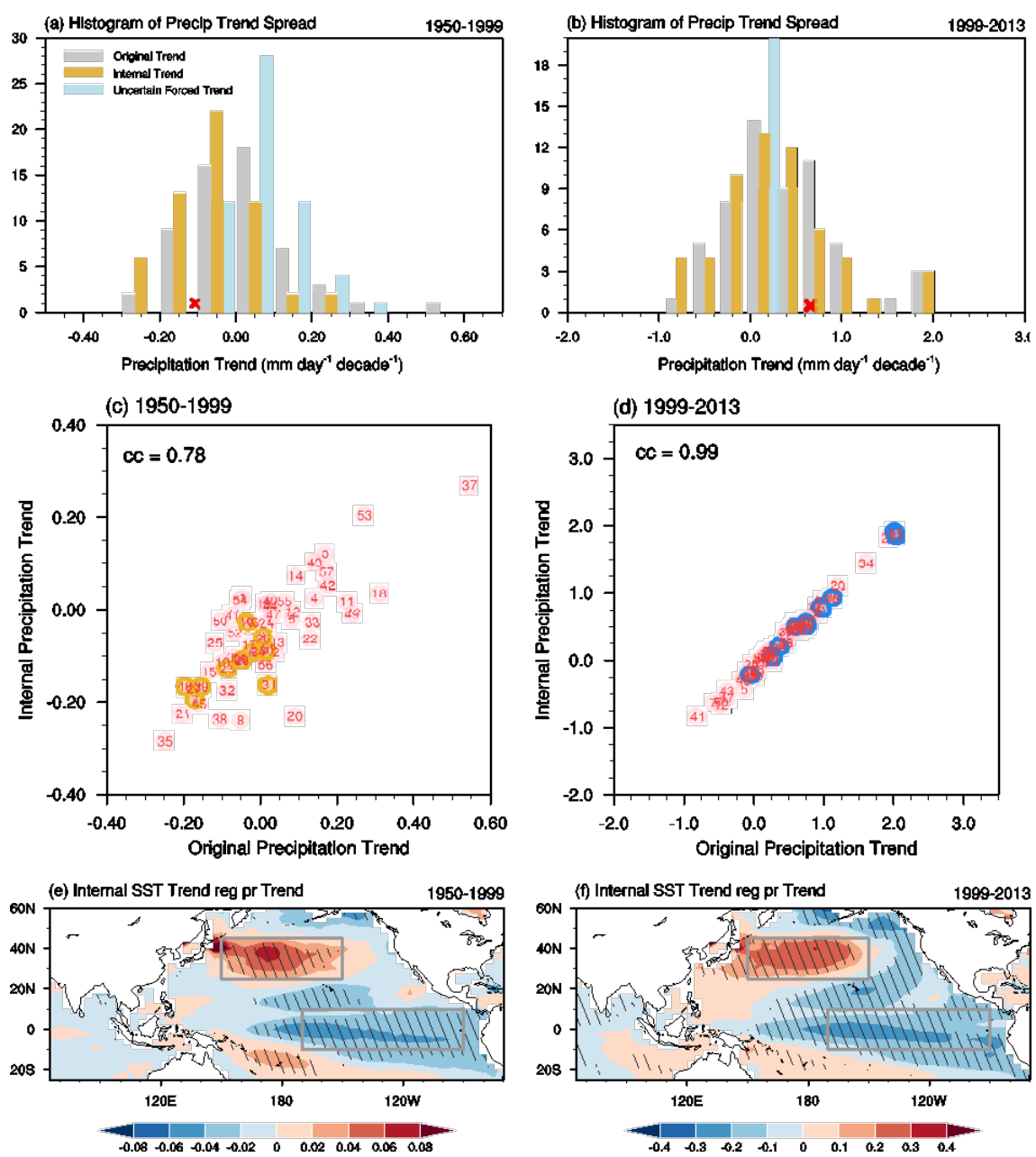

Fig. 6. Histograms of spread in NCI rainfall trends among 57 members during (a) 1950-1999 and (b) 1999-2013 (grey, yellow and blue bars denote the trends of the original rainfall, the internal component and the uncertain-forced component of rainfall). Correlation between trends of the original rainfall (x-bar, units: mm day ${ }^{-1}$ decade $^{-1}$ ) and the internal component of the rainfall (y-bar, units: $\mathrm{mm} \mathrm{day}^{-1}$ decade $^{-1}$ ) over the NCI region derived from ESPPE members (number indicated in the circle) during the period (c) 1950-1999 and (d) 1999-2013. (The outlined member " 37 " in c. is caused by the combination of a positive internal rainfall trend and an evidently positive forced trend.) Brown circles in (c) denote the 10 members with the strongest positive IPO phase transition during 1950-1999. Blue circles in (d) denote the 10 members with the strongest negative IPO phase transition during 1999-2013. The regression pattern of the internal SST trends with respect to the NCI rainfall trends across 57 members through the member index: (e) 1950-1999 and (f) 1999-2013 (units: K (decade) ${ }^{-1}$ ). Slant hatching denotes regions significant at the $95 \%$ confidence level. The rectangles in (e-f) outline the tropical central-eastern Pacific (TCEP, $170^{\circ} \mathrm{W}-90^{\circ} \mathrm{W}$, $\left.10^{\circ} \mathrm{S}-10^{\circ} \mathrm{N}\right)$ and the North Pacific $\left(\mathrm{NP}, 150^{\circ} \mathrm{E}-150^{\circ} \mathrm{W}, 25^{\circ} \mathrm{N}-45^{\circ} \mathrm{N}\right)$. 


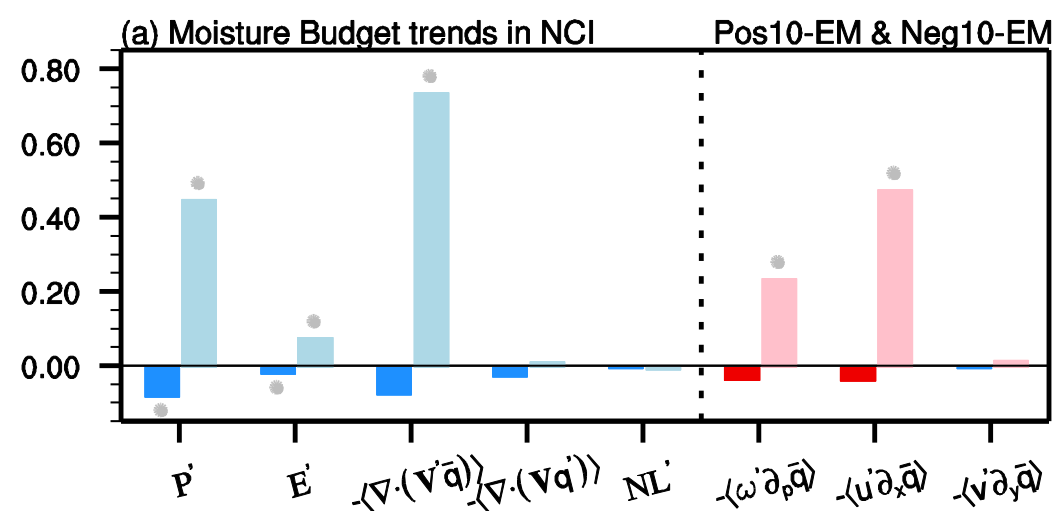

(b) $\mathrm{P}^{\prime}$

1950-1999

(c) $\mathrm{P}^{\prime}$ 1999-2013
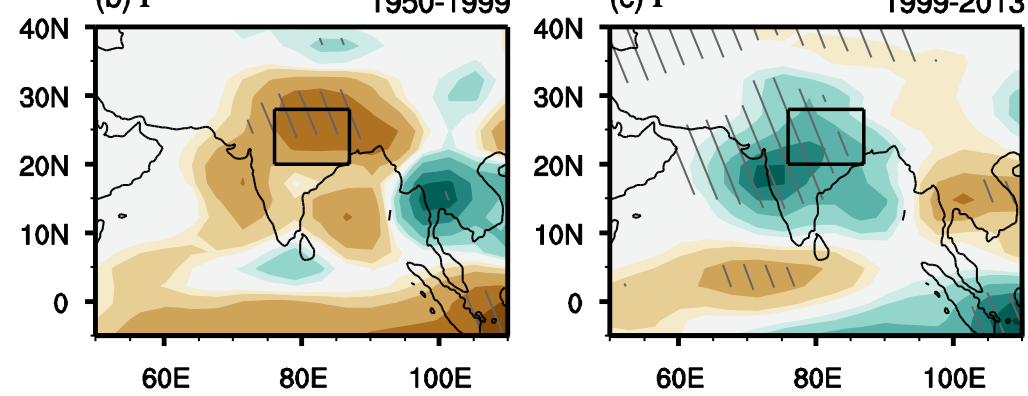

(d) $-\left\langle\nabla \cdot\left(V^{\prime} \bar{q}\right)\right\rangle \quad 1950-1999$
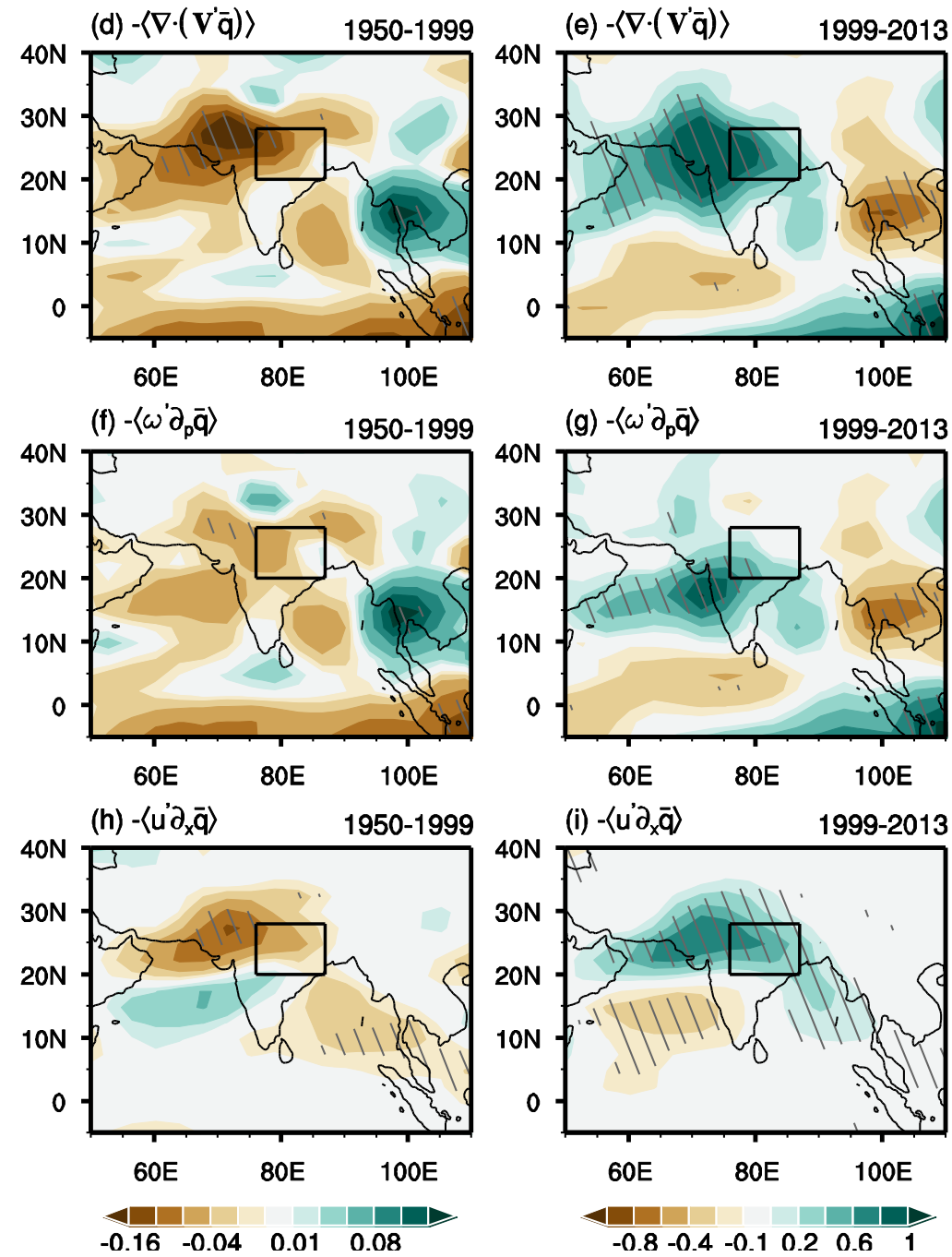
1133 Fig. 7. Moisture budget analysis of the rainfall trend related to IPO phase transitions. (a). Moisture budget analysis 1134 on NCI rainfall trend difference between the 10 members with the strongest positive IPO phase transition and 1135 ensemble mean during 1950-1999 (Pos10-EM; dark colour bars). Light colour bars are for Neg10-EM during 19992013. Dots denote trend differences significant at $95 \%$ confidence level. Rainfall change is balanced by the changes of evaporation, dynamic and thermodynamic components and a nonlinear term (blue and light blue bars). The dynamic component is further separated into vertical, zonal and meridional dynamic components of moisture advection (red and pink bars). (b, d, f, h) are spatial patterns of Pos 10-EM trend during 1950-1999 of rainfall, dynamic component, vertical dynamic component and zonal dynamic component of moisture advection, respectively. (c, e, g, i) are same as (b, d, f, h) but for Neg10-EM during 1999-2013. Units: mm day ${ }^{-1}$ decade $^{-1}$. Slant hatching denotes regions significant at $95 \%$ confidence level. 
(a) Pos10-EM VP \& Div_UV @200hPa

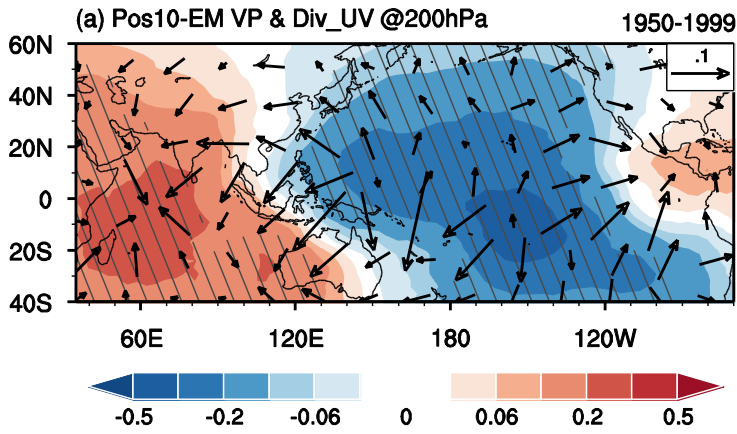

(c) Pos10-EM Precip \& 850hPa SF 1950-1999
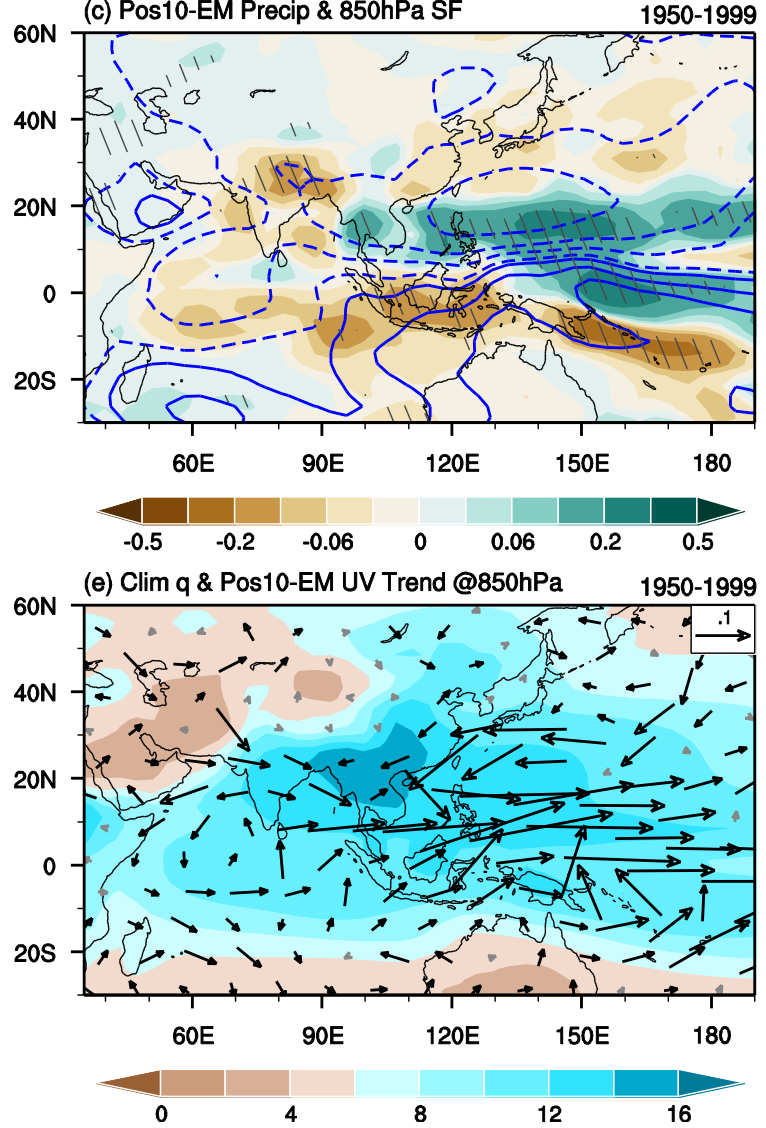

(b) Neg10-EM VP \& Div UV @200hPa
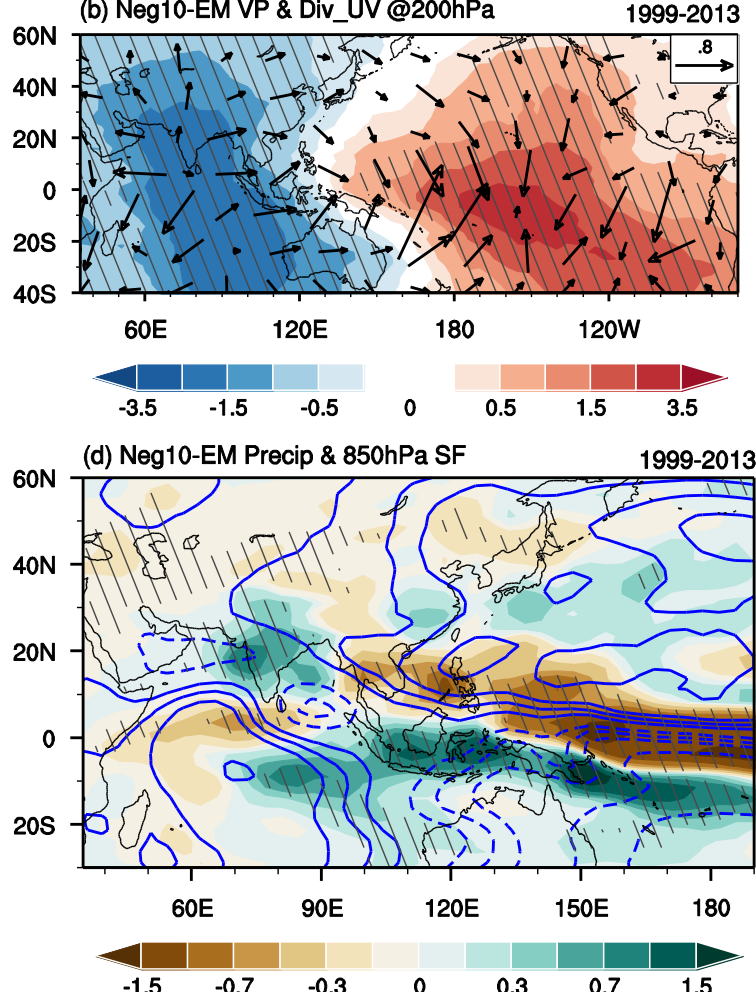

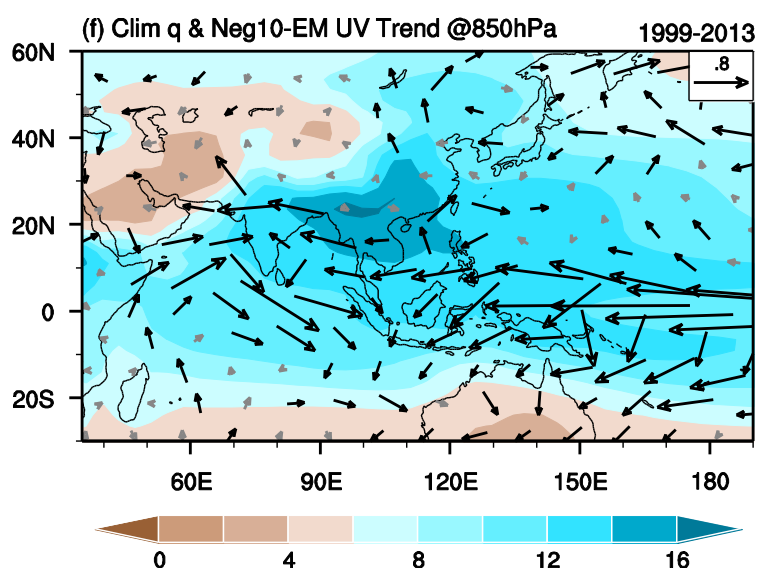

Fig. 8. Mechanisms of IPO's modulation of ISM rainfall reduction and revival. JJA trend differences between the 10 members with the strongest positive IPO phase transition and ensemble mean (Pos10-EM) from 1950-1999 for: (a) velocity potential (shading, units: $\mathrm{m}^{2} \mathrm{~s}^{-1}$ decade $^{-1}$ ) and divergent winds (vectors, units: $\mathrm{m} \mathrm{s}^{-1} \mathrm{decade}^{-1}$ ) at 200hPa; (c) rainfall (shading, units: $\mathrm{mm} \mathrm{day}^{-1}$ decade $^{-1}$ ) and $850 \mathrm{hPa}$ stream function anomalies (contours, units: $10^{6} \mathrm{~m}^{2} \mathrm{~s}^{-1} \mathrm{decade}^{-}$ ${ }^{1}$ ); (e) $850 \mathrm{hPa}$ winds (vectors, units: $\mathrm{m} \mathrm{s}^{-1}$ decade $^{-1}$ ) and climatological specific humidity (shading, units: g/kg). (b), (d) and (f) are the same as (a), (c) and (e) but for Neg10-EM trend differences in 1999-2013. Slant hatching denotes regions significant at $95 \%$ confidence level. 

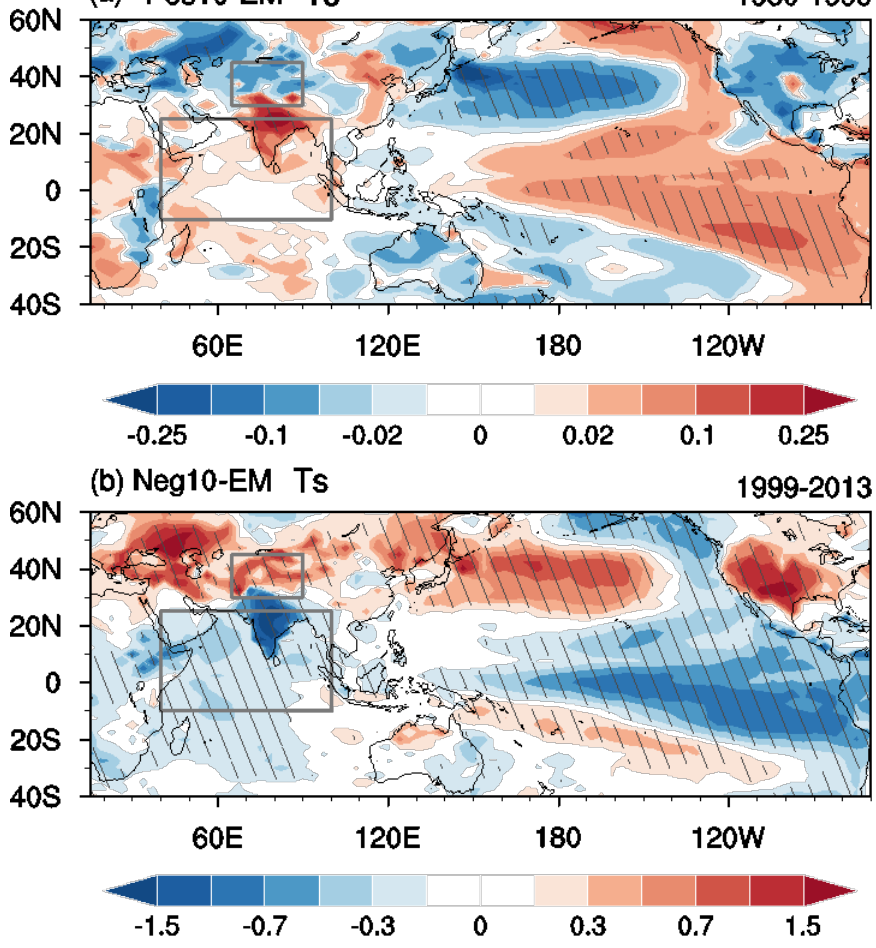

(c) Meridional Surface Temperature Gradient

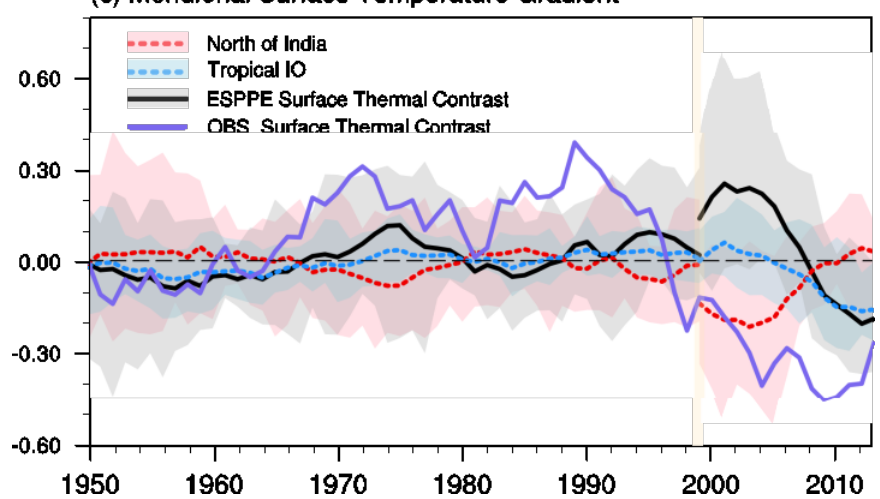

Fig. 9. JJA surface temperature trend related to IPO phase transitions. (a) Spatial patterns of the trend differences of the JJA surface temperature between the 10 members with the strongest positive IPO phase transition and ensemble mean (Pos10-EM) during 1950-1999. (b) is the same as (a) but for trend differences of Neg10-EM during 1999-2013. (c) Composite 9-year running mean anomalies (relative to 1950-2013 mean) derived from the Pos10-EM composite difference for 1950-1999 and the Neg10-EM composite difference for 1999-2013 for surface air temperature over the landmass north of India (red, land area in $30^{\circ} \mathrm{N}-45^{\circ} \mathrm{N}, 65^{\circ} \mathrm{E}-90^{\circ} \mathrm{E}$ ), SST over the tropical Indian Ocean (blue, ocean area over the $10^{\circ} \mathrm{S}-25^{\circ} \mathrm{N}, 40^{\circ} \mathrm{E}-100^{\circ} \mathrm{E}$ ) and the land-sea thermal contrast (black, i.e., the difference between the red and blue lines). The purple line denotes the observed land-sea surface thermal contrast derived from the CRUTEM4 and HadISST datasets. 
(a) Pos10-EM Z200-500
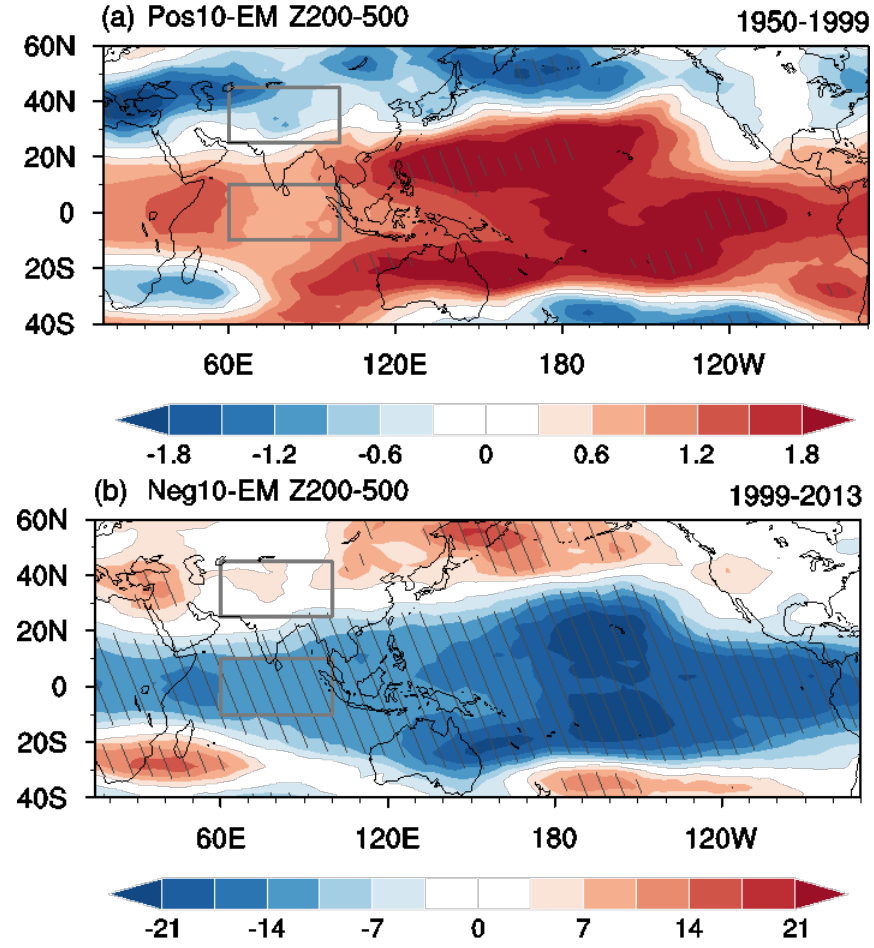

(c) Meridional 500-200hpa Tropospheric Thickness Gradient

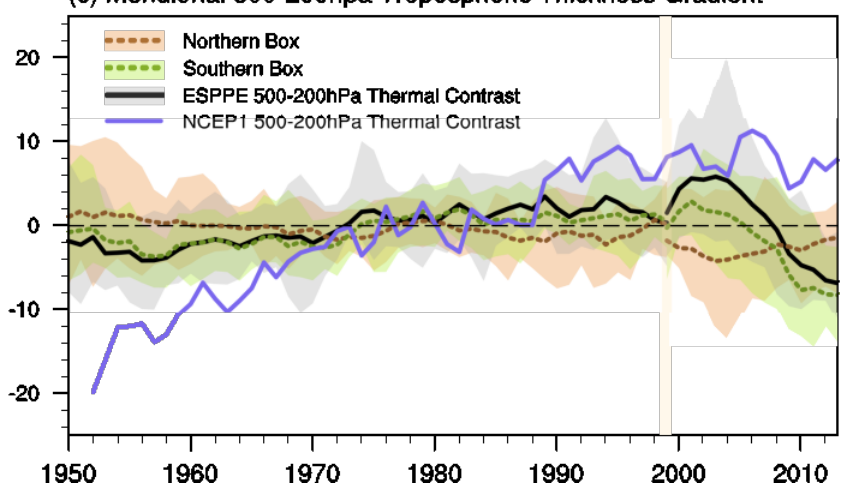

Fig. 10. JJA mid-upper tropospheric thickness trend related to IPO phase transitions. (a) Spatial patterns of the trend differences of the JJA 500-200hPa tropospheric thickness between the 10 members with the strongest positive and the ensemble mean (Pos10-EM) during 1950-1999. (b) is the same as (a) but for trend differences of Neg10-EM during 1999-2013. (c) Composite 9-year running mean anomalies (relative to 1950-2013 mean) derived from the Pos10-EM composite difference for 1950-1999 and the Neg10-EM composite difference for 1999-2013 for 500$200 \mathrm{hPa}$ tropospheric thickness over Eurasia (brown, the northern box over $25^{\circ} \mathrm{N}-45^{\circ} \mathrm{N}, 60^{\circ} \mathrm{E}-100^{\circ} \mathrm{E}$ in a-b), the tropical Indian Ocean (green, the southern box over $10^{\circ} \mathrm{S}-10^{\circ} \mathrm{N}, 60^{\circ} \mathrm{E}-100^{\circ} \mathrm{E}$ in $\mathrm{a}-\mathrm{b}$ ) and the meridional thermal gradient over India (black, i.e., the difference between the brown and green lines). The purple line denotes the meridional 500-200hPa tropospheric thickness gradient derived from the NCEP/NCAR reanalysis. 

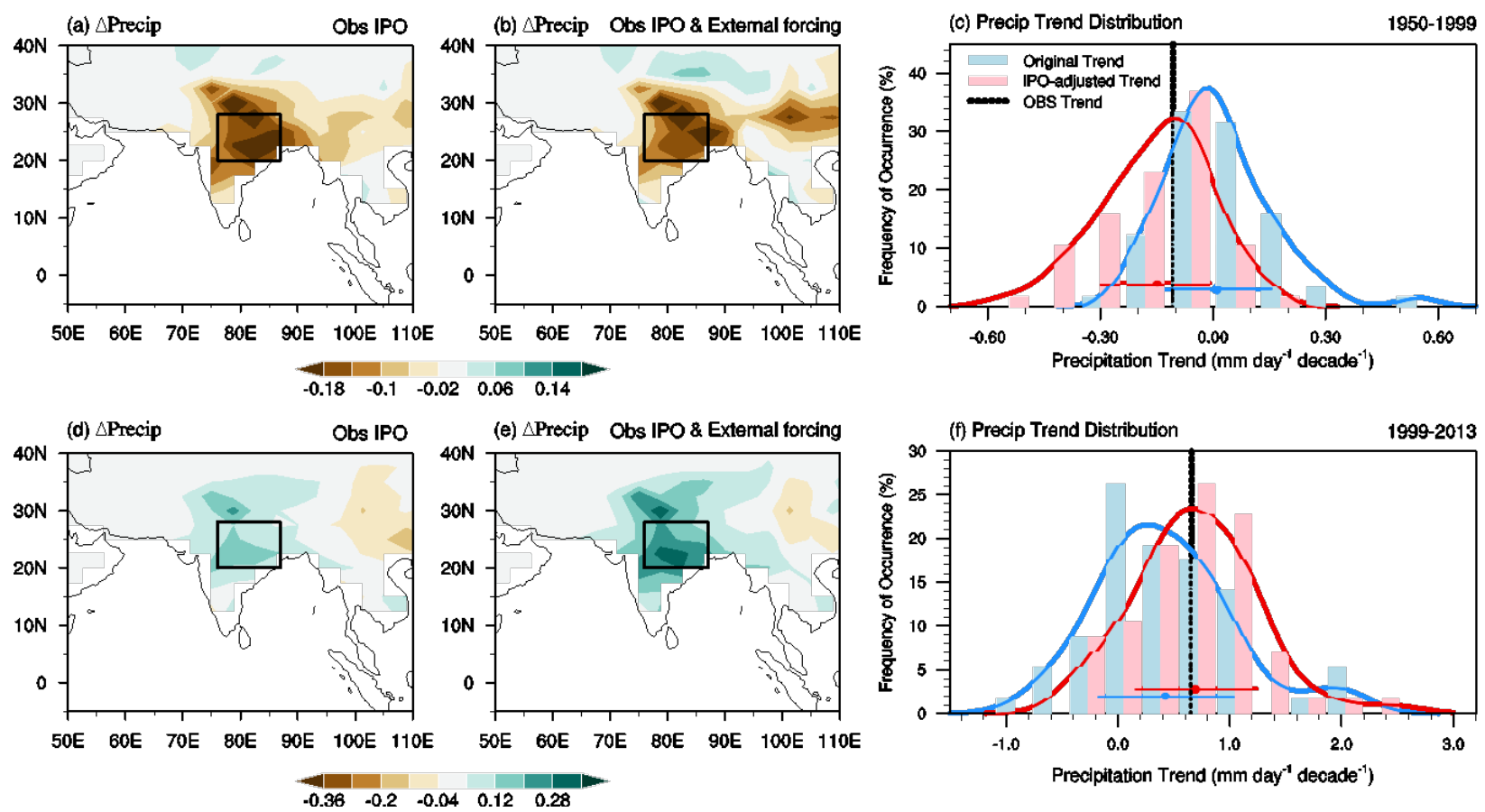

Fig. 11. Adjustments of the ISM rainfall trends according to the IPO phase transition. (a) EM of the IPO-adjusted internal JJA rainfall trends $\left(\partial_{t} p r_{\text {internal_adj }}\right)$ in ESPPE during 1950-1999, representing the rainfall trend caused by the observed IPO phase transition. (b) EM of the IPO-adjusted total JJA rainfall trends $\left(\partial_{t} p r_{a d j}\right)$ in ESPPE during 1950-1999, representing the rainfall trend caused by both the external forcing and the observed IPO. (c) Histograms (bars) and fitted distribution with 100 bins (lines) of the area-averaged rainfall trends over the NCI region during 1950-1999 derived from the 57 ESPPE members. The blue bars and the fitted blue curves show the frequency of occurrence of the original rainfall trends, with the blue dot and horizontal blue line denote the EM and STD of $0.01 \pm$ 0.14. The red bars and the fitted red curves show the frequency of occurrence of the rainfall trends with adjustments accounting for the influence of the observational IPO phase transition (red dot and horizontal red line denote the EM and STD of $-0.15 \pm 0.13$. (d-f) are same as (a-c) but for 1999-2013. The EM and STD for the blue and red bars in (f) are $0.42 \pm 0.61$ and $0.68 \pm 0.54$, respectively. The black dashed lines in (c) and (f) denote the observed NCI rainfall trends of -0.11 and 0.66 , respectively. Units: $m m$ day $^{-1}$ decade $^{-1}$. 

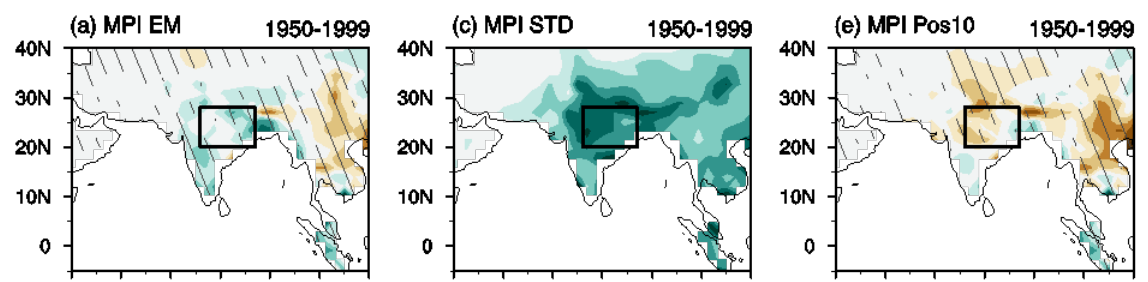

5OE 60E 70E 80E 90E 100E 110 E 50E 60 E 70 E 80 E 90E 100E 110 E 50E 60 E 70E 80 E 90E 100 E 110 E
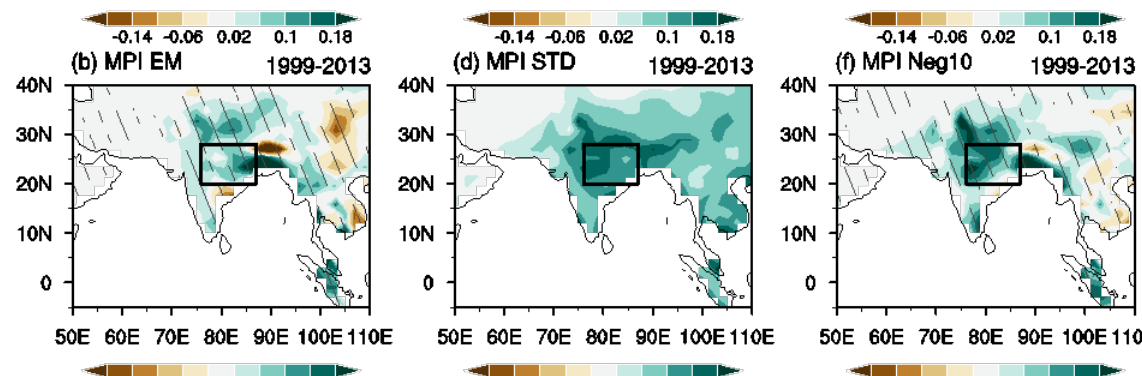

$\begin{array}{lllll}-0.21 & 0.09 & 0.03 & 0.15 & 0.27\end{array}$

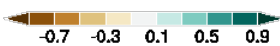

50E 60 E 70 E 80 E 90E 100 E 110 E

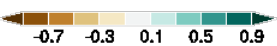

(g) Time Series of NCI Precip

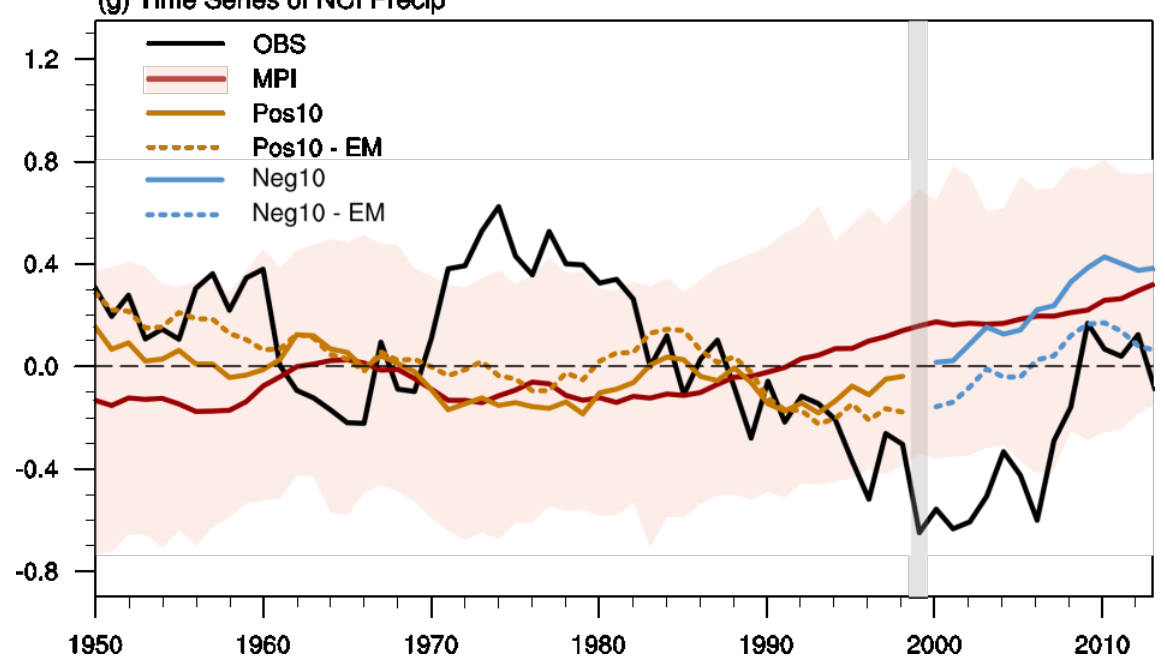

Fig. 12. Spatial patterns of 9-year running-mean JJA rainfall trends during the period of (a) 1950-1999 and (b) 19992013 derived from the EM of the 100-member MPI-ESM ensemble. The STD of the rainfall trends among the 100 MPI-ESM members for (c) 1950-1999 and (d) 1999-2013. Rainfall trends derived from (e) the 10 members with the strongest positive IPO phase transition (Pos10) during 1950-1999, (f) the 10 members with the strongest negative IPO phase transition (Neg10) during 1999-2013. Units: $\mathrm{mm} \mathrm{day}^{-1}$ decade $^{-1}$. Slant hatching denotes trends significant at the $95 \%$ confidence level. (g) Time series of the 9-year running-mean of JJA rainfall anomalies averaged over NCI. Units: $\mathrm{mm}$ day ${ }^{-1}$. Black is for the OBS. Red line and shading denote the EM and $5^{\text {th }}$ and $95^{\text {th }}$ percentile of the 100 members. Brown and blue solid lines represent the mean of Pos10 and Neg10 members during 1950-1999 and 19992013, respectively. Brown and blue dashed lines represent the mean difference of the Pos 10 minus EM during 19501999 and the Neg10 minus EM during 1999-2013. 

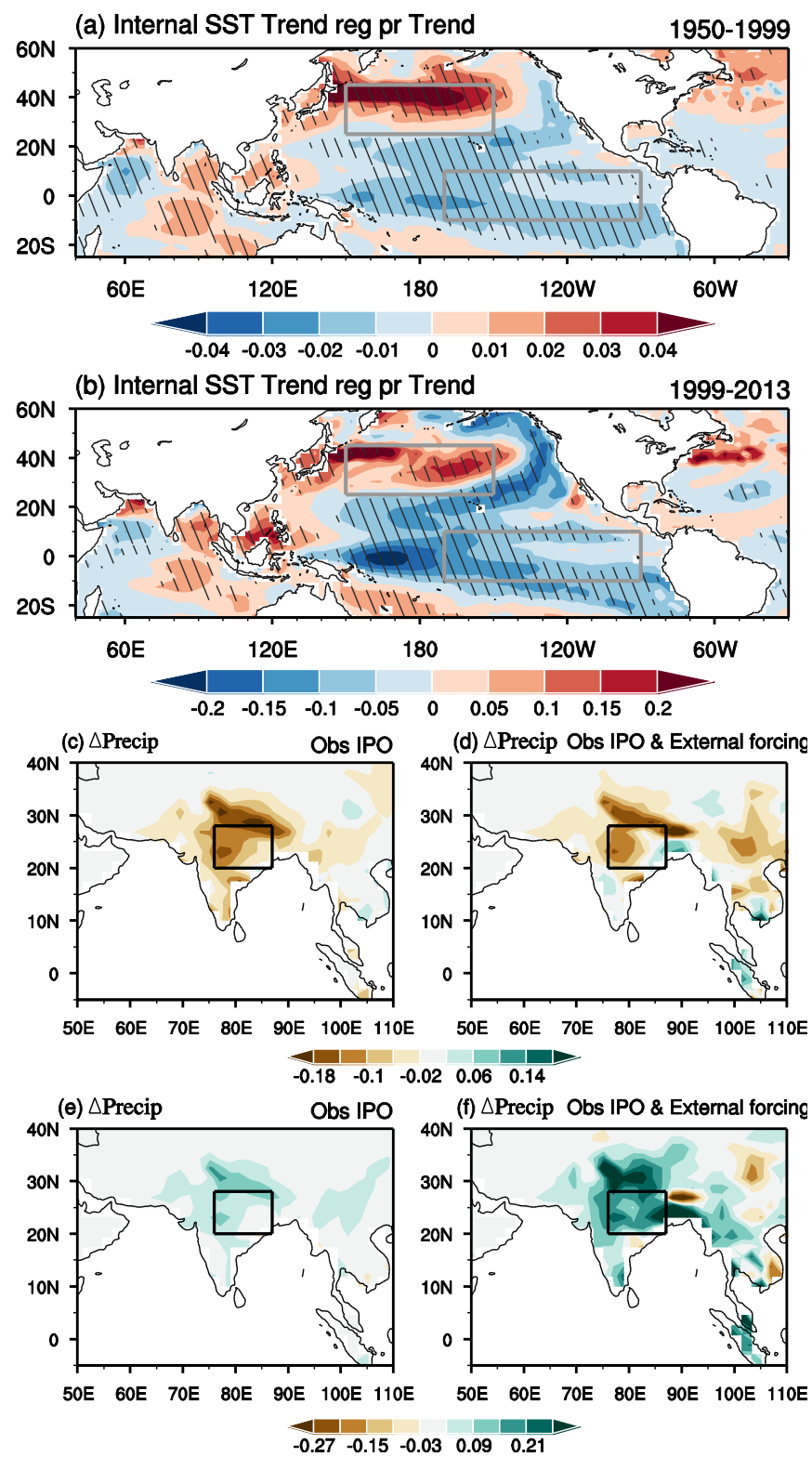

1204 Fig. 13. The regression pattern of the internal SST trends with respect to the NCI rainfall trends across 100 members through the member index: (a) 1950-1999 and (b) 1999-2013 (units: K (decade) ${ }^{-1}$ ). Slant hatching denotes regions significant at the $95 \%$ confidence level. (c) EM of the IPO-adjusted internal JJA rainfall trends ( $\partial_{t}$ pr $\left.r_{\text {internal_adj }}\right)$ in MPI-ESM during 1950-1999, representing the rainfall trend caused by the observed IPO phase transition. (d) EM of the IPO-adjusted total JJA rainfall trends $\left(\partial_{t} p r_{a d j}\right)$ in MPI-ESM during 1950-1999, representing the rainfall trend caused by both the external forcing and the observed IPO. (e-f) are same as (c-d) but for 1999-2013. Units: mm day $1210{ }^{1}$ decade $^{-1}$. 
(a) External forcing (1950-1999)

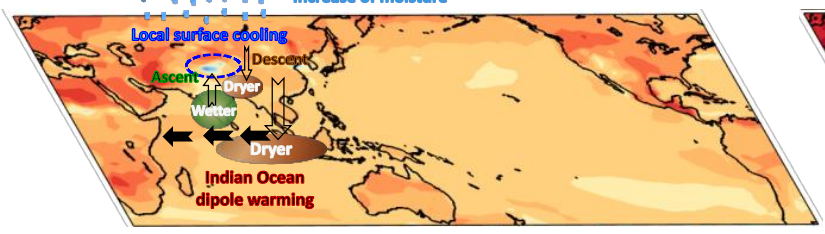

(b) External forcing (1999-2013)

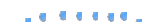

- Greater increase of moisture

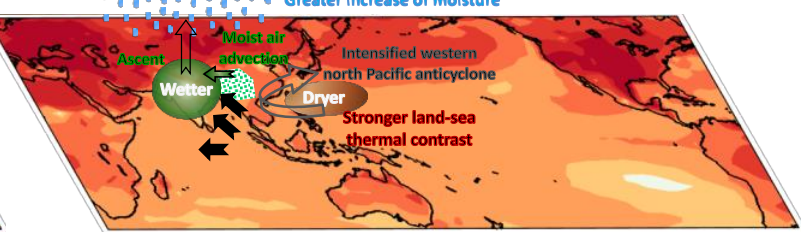

(d) Internal variability (1999-2013)

(c) Internal variability (1950-1999)
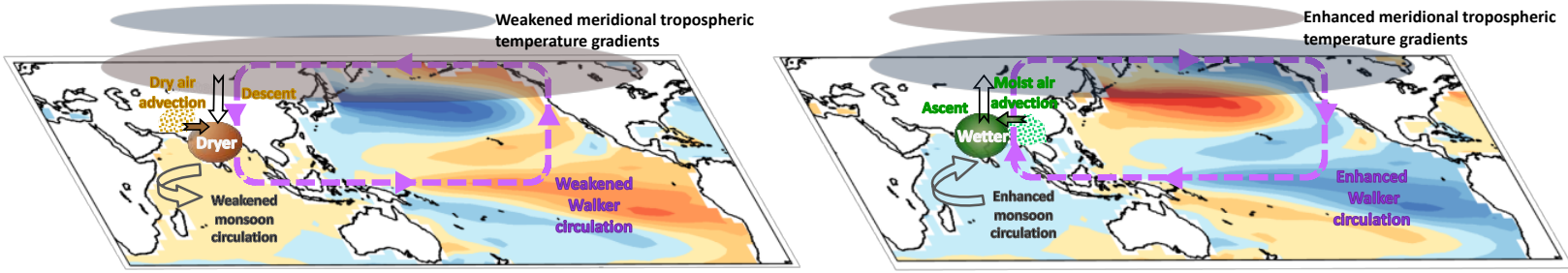

1213 Fig. 14. Schematic diagrams showing how external forcing and internal variability affect the recent decline and 1214 recovery of ISM rainfall, respectively. 